\title{
Gamma Prime Precipitation, Dislocation Densities and TiN in Creep-Exposed Inconel 617 Alloy
}

\author{
R. KRISHNA ${ }^{1,2}$, H.V. ATKINSON ${ }^{1, *}$, S.V. HAINSWORTH ${ }^{1}$, AND S.P.A. GILL ${ }^{1}$ \\ ${ }^{1}$ Department of Engineering, University of Leicester, University Road, Leicester, LE1 7RH, \\ UK
}
${ }^{2}$ Now at Dalton Cumbrian Facility, University of Manchester, Westlakes Science and Technology Park, Moor Row, Whitehaven, Cumbria, CA 24 3HA, UK

* Corresponding author, hva2@le.ac.uk

Inconel 617 is a solid solution strengthened Ni-based superalloy with a small amount of gamma prime $\left(\gamma^{\prime}\right)$ present. Here samples are examined in the as-received condition and after creepexposure at $923 \mathrm{~K}\left(650^{\circ} \mathrm{C}\right)$ for 574 hours and 45,000 hours and at $973 \mathrm{~K}\left(700^{\circ} \mathrm{C}\right)$ for 4,000 hours. The stress levels are intermediate (estimated respectively as of the order of 350,275, and 200MPa) and at levels of interest for the future operation of power plant. The hardness of the specimens has been measured in the gauge length and the head. TEM thin foils have been obtained to quantify dislocation densities $\left(3.5 \times 10^{13}\right.$ for the as-received, $5.0 \times 10^{14}, 5.9 \times 10^{14}$ and $3.5 \times 10^{14}$ lines $/ \mathrm{m}^{2}$ for the creep exposed specimens respectively). There is no previous data in the literature for dislocation densities in this alloy after creep exposure. There is some evidence from the dislocation densities that for the creep exposed samples the higher hardness in the gauge length in comparison with the creep test specimen head is due to work hardening rather than any other effect. Carbon replicas have been used to extract gamma prime precipitates. The morphology of $\gamma^{\prime}$ precipitates in the 'as-received' condition was spheroidal with an average diameter of $18 \mathrm{~nm}$. The morphology of these particles does not change with creep exposure but the size increases to $30 \mathrm{~nm}$ after 574 hours at $923 \mathrm{~K}\left(650^{\circ} \mathrm{C}\right)$ but with little coarsening in 45,000 hours. At $973 \mathrm{~K}\left(700^{\circ} \mathrm{C}\right) 4000$ hours, the average gamma prime size is 32 $\mathrm{nm}$. In the TEM images of the replicas the particles overlap and therefore a methodology has been developed to estimate the volume fraction of gamma prime in the alloy given the carbon replica film thickness. The results are $5.8 \mathrm{vol} \%$ in the as-received and then $2.9,3.2$ and $3.4 \mathrm{vol} \%$ respectively for the creep exposed specimens. The results are compared with predictions from thermodynamic analysis given the alloy compositions. Thermodynamic prediction shows that nitrogen content is important in determining the gamma prime volume fraction. This has not previously been identified in the literature. The higher the nitrogen content, the lower the gamma prime volume fraction. This may explain inconsistencies between previous experimental estimates of gamma prime volume fraction in the literature and the results here. The observed decrease in the $\gamma^{\prime}$ volume fraction with creep exposure would correspond to an increase in TiN. At present there is insufficient experimental data to prove this predicted relationship occurs in practice. However, it is observed that there is a higher volume fraction of TiN precipitates in the gauge length of a creep sample than in the head. This suggests that secondary TiN particles are precipitating at the expense of existing $\gamma^{\prime}$ due to the ingress of $\mathrm{N}$ from the atmosphere, possibly via creep cracks penetrating in from the surface of the gauge length. This effect is not expected to be observed in real components which are much larger and operate in different atmospheres. However, this highlights the need to be conscious of this possibility when carrying out creep testing. 
Keywords: Inconel 617, Hardness, Gamma prime $\left(\gamma^{\prime}\right)$ Precipitates, TEM, Thermo-Calc, Volume fraction, Dislocation density, Thermodynamic prediction

\section{INTRODUCTION}

Inconel 617 (UNS N06617) was originally introduced by Hosier and Tillack in $1972^{[1]}$ and is a solid-solution strengthened austenitic Ni-based superalloy containing $23 \mathrm{wt} . \% \mathrm{Cr}, 12 \mathrm{wt} . \% \mathrm{Co}$, and 9 wt. \% Mo with small additions of $\mathrm{Al}, \mathrm{Ti}$ and $\mathrm{Fe}$. Cobalt and molybdenum are responsible for providing solid solution strengthening whilst aluminium and chromium confer the oxidation resistance at high temperatures. This alloy is one of the preferred structural materials for steam boilers and turbines components to be used in advanced fossil fuelled power plants to accommodate demanding operating conditions. Inconel 617 has been successfully used at temperatures up to $600^{\circ} \mathrm{C}$ in conventional fossil fuelled power plants and is currently being investigated for higher temperature applications in advanced steam power plants ('ultrasupercritical') envisioned to operate at $973 \mathrm{~K}$ $\left(700^{\circ} \mathrm{C}\right) / 37.5 \mathrm{MPa}$ and above. ${ }^{[1-4]}$ There have been recent studies on this particular alloy at higher temperatures $\left(1073 \mathrm{~K}\left(800^{\circ} \mathrm{C}\right)\right.$ and above) for heat exchanger applications in nuclear power reactors (e.g. Chomette et al., ${ }^{[5]}$ Kaoumi and Hrutkay ${ }^{[6]}$ and Roy et al. ${ }^{[7]}$ ) but this study focusses on the $923 \mathrm{~K} / 973 \mathrm{~K}\left(650^{\circ} \mathrm{C} / 700^{\circ} \mathrm{C}\right)$ regime more suited to steam power plant.

In addition to solid solution strengthening, the grain structure of Inconel 617 is stabilised by precipitation of carbides and some strengthening of the alloy is derived from inter- and intra-granular carbides and carbo-nitrides of types $\mathrm{M}_{23} \mathrm{C}_{6}$ and $\mathrm{Ti}(\mathrm{C}, \mathrm{N}) \cdot{ }^{[8]}$ Titanium and aluminium may additionally contribute to precipitation hardening through intermetallic precipitation of $\gamma^{\prime}$. After exposure to high temperature $1273 \mathrm{~K}\left(1000^{\circ} \mathrm{C}\right)$ and creep conditions, precipitation and coarsening continually remove strengthening elements from the $\gamma$-matrix and significantly degrade the high temperature creep and mechanical properties of the alloy. ${ }^{[9,10]}$ Several structural characterization studies ${ }^{[11-20]}$ have been conducted on thermally and creep-exposed Inconel 617 alloys. These papers have been primarily focused on the precipitation of $\mathrm{M}_{23} \mathrm{C}_{6}$ and $\mathrm{Ti}(\mathrm{C}, \mathrm{N})$ in the thermal and creep exposed alloy and there has been less emphasis on the role of $\gamma^{\prime}$ in the microstructure.

In previous studies of $\gamma^{\prime}$ in Inconel 617, Mankins et al ${ }^{[8]}$ performed a study on samples exposed for 215 to 10,000 hours at temperatures up to $1366 \mathrm{~K}\left(1093^{\circ} \mathrm{C}\right)$. The major precipitate that was found after exposure was $\mathrm{M}_{23} \mathrm{C}_{6}$ with no $\mathrm{MC}$ or $\mathrm{M}_{6} \mathrm{C}$ carbides. They found small amounts of $\gamma^{\prime}$ in samples exposed at $922 \mathrm{~K}$ and $1033 \mathrm{~K}\left(649\right.$ and $\left.760^{\circ} \mathrm{C}\right)$. The maximum expected $\gamma^{\prime}$ content was predicted to be $0.63 \mathrm{pct}$. Penkalla et al. ${ }^{[13]}$ observed $\gamma^{\prime}$ precipitates in thermally exposed Inconel 617 samples at $973 \mathrm{~K}\left(700^{\circ} \mathrm{C}\right)$ and $1023 \mathrm{~K}\left(750^{\circ} \mathrm{C}\right)$ after durations of $80 \mathrm{~h}$ and $5,000 \mathrm{~h}$, respectively. $\gamma^{\prime}-$ precipitates were observed in the thermally exposed samples and were in the size range of 20 to $90 \mathrm{~nm}$ with a volume fraction up to 4 pct. Gariboldi et $a l^{[14]}$ reported spherical and cuboidal $\gamma^{\prime}$ precipitates of average size 60 and $225 \mathrm{~nm}$ in creep-exposed alloy at $973 \mathrm{~K}$ and $1073 \mathrm{~K}\left(700^{\circ} \mathrm{C}\right.$ and $\left.800^{\circ} \mathrm{C}\right)$ respectively. Wu et al. ${ }^{[15]}$ observed nearly spheroidal $\gamma^{\prime}$ precipitates for long exposure up to $65,600 \mathrm{~h}$ and $1144 \mathrm{~K}\left(871^{\circ} \mathrm{C}\right)$, in the size range from a minimum of $10 \mathrm{~nm}$ to maximum of $200 \mathrm{~nm}$. A significant reduction in volume fraction ranging from a maximum of $5 \mathrm{pct}$ at $866 \mathrm{~K}\left(593^{\circ} \mathrm{C}\right)$ to minimum less than $1 \mathrm{pct}$ at $1144 \mathrm{~K}\left(871^{\circ} \mathrm{C}\right)$ was reported. They have plotted TTT diagrams for the long term aged samples. $\gamma^{\prime}$-precipitates are also discussed by Kimball et al. ${ }^{[16]}$, Takahashi et al. ${ }^{[17]}$, and Kirchhöfer et al. ${ }^{[18]}$, in aged Inconel 617 in the $866 \mathrm{~K}$ to $1323 \mathrm{~K}\left(593\right.$ to $\left.1050^{\circ} \mathrm{C}\right)$ temperature range.

At both temperatures in this study, the precipitates at equilibrium are predicted in previous work by the authors ${ }^{[20]}$ to be $\gamma^{\prime}, \operatorname{TiN}_{,} \mathrm{M}_{23} \mathrm{C}_{6}$ and $\mu$-phase. The first three of these phases are observed 
in the as-received material, whereas $\mu$-phase is only observed in the creep specimens tested beyond 1000 hours. ${ }^{[20]}$ In the previous work, ${ }^{[20]}$ the $\mathrm{M}_{23} \mathrm{C}_{6}$ carbides are expected to precipitate out on the grain-boundaries within the first 10-100 hours, depending on the grain size. The quantity is essentially limited by the carbon content of the material and hence is predicted to be $1.4 \mathrm{~mol} \%$ at both temperatures at equilibrium. This equates to a volume fraction of $1.1 \%$. It almost continuously plates the grain boundaries with particles 1-10 microns in size.

In this study, Inconel 617 is examined in the as-received and creep-exposed state with the creep exposure conditions relevant to potential future power generation power plant operating temperatures of $923 \mathrm{~K}\left(650^{\circ} \mathrm{C}\right)$ and $973 \mathrm{~K}\left(700^{\circ} \mathrm{C}\right)$. The hardness of specimens is measured in the gauge length and head. Dislocation densities are measured in TEM thin foils as this is relevant to understanding hardness and creep behaviour and there is no previous data on dislocation densities in the literature. The morphology and size of $\gamma^{\prime}$ precipitates is identified from carbon replicas to assess the long term stability and the volume fraction compared with the volume fraction predicted using thermodynamic prediction software. The thermodynamic prediction work carried out here builds on that reported previously ${ }^{[20]}$ and focusses on the interrelationship between $\gamma^{\prime}$ and nitrogen content. The content of TiN particles has therefore been assessed by SEM in one sample as an exemplar, comparing the edge region with the centre of the sample. In addition, TEM carbon replicas of that exemplar sample have been examined for small TiN particles of a size difficult to observe in the SEM.

\section{MATERIALS \& EXPERIMENTAL PROCEDURES}

Saarschmiede GmbH Freiformschmiede manufactured and supplied the Inconel 617 alloy in the form of forged rods of diameter $700 \mathrm{~mm}$. The complete nominal chemical composition (as provided by the manufacturer) is shown in Table 1 .

The specimens used for creep rupture tests in the present investigation were prepared from solutionannealed $\left(1373 \mathrm{~K}\left(1100^{\circ} \mathrm{C}\right) / 3 \mathrm{Hrs} / \mathrm{WQ}\right)$ forged rods of Inconel 617 alloy, which were given a standard heat-treatment $\left(943 \mathrm{~K}\left(670^{\circ} \mathrm{C}\right) / 10 \mathrm{Hrs} / \mathrm{AC}\right)$ prior to machining to form creep specimens (see Fig. 1). In this study, two different types of creep rupture specimens were used, the type in Fig. 1 (a) for the test at $923 \mathrm{~K}\left(650^{\circ} \mathrm{C}\right)$ which led to a lifetime of $45,000 \mathrm{~h}$ and for the test at $973 \mathrm{~K}\left(700^{\circ} \mathrm{C}\right)$ which led to a lifetime of $4000 \mathrm{~h}$, and the type in Fig. 1 (b) for the test at $923 \mathrm{~K}\left(650^{\circ} \mathrm{C}\right)$ which led to a lifetime of 574h. The type in Fig. 1 (b) is relevant when testing for notch sensitivity at the same time as for an unnotched gauge length. The specimen is monitored by 3 thermocouples and maintained within a $3^{\circ} \mathrm{C}$ spread, as per the controlling standard. The head or fittings are not monitored during the test, but are within the same portion of the 3 zone furnace. If there was a thermal gradient it is expected that the maximum would be up to $5^{\circ} \mathrm{C}$. The stresses are respectively estimated (based on the published literature in Ennis and Quadakkers ${ }^{[22]}$ and Chandra et al. ${ }^{[12]}$ ) as of the order of $350 \mathrm{MPa}, 275 \mathrm{MPa}$ and 200MPa. Crept specimens were examined after rupture using metallography, hardness testing and transmission electron microscopy (TEM). Fig. 2 shows where the TEM samples were taken from and the locations of hardness measurements.

\section{Metallography and Grain Size Measurement}


Metallographic specimens were prepared from the head and gauge length of each creep specimen. Specimens were mounted in phenolic resin, successively polished with $\mathrm{SiC}$ abrasive papers from 600 to 1200 grit using diamond slurries $(9-3 \mu \mathrm{m})$ and colloidal silica $(0.05 \mu \mathrm{m})$. Finally, the polished surface was etched in glyceregia which is a mixture of hydrochloric acid, glycerol and nitric acid in a $3: 2: 1$ ratio.

The linear intercept method was used for the measurement of average grain size on optical micrographs.

\section{Hardness Measurement}

Vickers hardness tests were conducted using a Vickers hardness testing machine (Hardness Control Services Ltd. UK), with a load of $20 \mathrm{kgf}$ and 10 s dwell time on ground and polished longitudinal cross-sections of the creep fractured specimens. Indents were made every $2 \mathrm{~mm}$ along the longitudinal axis and with three indents across the diameter at intervals of $2 \mathrm{~mm}$. The hardness value at each position along the length of the specimen was the average of three hardness values across the diameter of the specimen. The measurements were conducted on the head and gauge length.

\section{Specimen Preparation Techniques for TEM Analysis}

Thin foil samples for TEM were prepared from the gauge length of the creep-exposed samples. To avoid introducing dislocations during sectioning and polishing of thin film samples for TEM, firstly a low speed diamond wheel saw with a controlled rotational speed was used to obtain a thin section $(0.10 \mathrm{~mm}$ to $0.12 \mathrm{~mm})$ of the bulk specimen. Mechanical polishing was then conducted using progressively finer $\mathrm{SiC}$ grit papers and water and diamond slurry suspension. The diamond slurry minimizes and removes damaged surface layers introduced during the previous steps. $3 \mathrm{~mm}$ discs were then cut with a disc punch designed to avoid compression and distortion of the sample and further thinning was carried out to a thickness of 40-70 $\mu \mathrm{m}$ using a Disc Grinder (Gatan Model 623) on the lapping discs $(40 \mu \mathrm{m}, 15 \mu \mathrm{m}$ and $5 \mu \mathrm{m})$ in sequence to produce a highly polished surface. The Disc Grinder was used for the final mechanical thinning to obtain parallel-sided samples with minimal surface damage. The final thinning process was twin-jet electropolishing (Model: 120; Fischione Instrument, USA) in an electro-polishing solution of methanol (MeOH) with 20vol. \% perchloric acid $\left(\mathrm{HClO}_{4}\right)$ at $251 \mathrm{~K}\left(-22^{\circ} \mathrm{C}\right)$ under an applied potential of $14 \mathrm{~V}$ until an electron transparent region was obtained.

The gauge length of the creep-exposed samples was also used for obtaining carbon extraction replicas with a modified standard procedure. ${ }^{[19,20]}$ The diamond fine polished samples were firstly electro-polished to remove the surface damage layer. This electro-polishing was achieved using a platinum wire in a solution of $10 \% \mathrm{HCl}, 89 \%$ methanol and $1 \%$ citric acid at a voltage of $25 \mathrm{~V}$ DC. Immediately after electro-polishing, the samples were deeply etched with Kalling's modified reagent (40 $\mathrm{ml}$ distilled water, $480 \mathrm{ml} \mathrm{HCl}$ and $48 \mathrm{gm}$ of $\mathrm{CuCl}_{2}$ ) at room temperature for $5 \mathrm{~min}$. After etching, the area of interest was observed under a low magnification microscope and the remaining area was carefully covered by a masking tape. The extraction replicas were prepared by evaporating carbon films ( $20-25 \mathrm{~nm}$ thick) onto the surface. After carbon film coating, the masking tape was removed and the carbon film was scored into approximately $3 \mathrm{~mm}^{2}$ areas. This aided the release of the film and allowed the electrolyte to penetrate beneath the carbon coating to help remove it during the final 
stages with ease. After scoring, the specimen was electrolytically re-etched, with a solution of $10 \mathrm{ml}$ $\mathrm{HCl}$ and $1 \mathrm{gm}$ tartaric acid in $90 \mathrm{ml}$ methanol at $4 \mathrm{~V}$. The replicas were lifted from the specimen surface by sliding the specimen gently into a bath of de-ionized water at an angle of $\sim 30^{\circ}$ to the surface of the water. The replicas were left in the bath for several minutes to allow any residual electrolyte to disperse from the surface, and they were then collected onto 200 mesh $\mathrm{Cu}$ support grids and dried before TEM observations. The thin foils and replicas were examined in a JEOL (Tokyo, Japan) JEM$2100 \mathrm{LaB}_{6}$ TEM operating at an accelerating voltage of $200 \mathrm{kV}$.

\section{Determination of $\gamma^{\prime}$ Volume Fraction}

The TEM image of gamma prime particles gives the superimposed view through a crosssection of material of a number of particles at different depths, as in Fig. 3(a). The resulting observed area fraction (see Fig. 3(b)) is not the same as the volume fraction of the particles, as particles are imaged through the entire thickness, not just on the top surface. Also, for the high particle densities we are observing, the effect of particle overlap is very significant.

The effect of overlap can be taken into consideration in the same way that the impingement of nuclei of growing phases can be accounted for in the Kolmogarov-Johnson-Avrami-Mehl equation. ${ }^{[23,24]}$ The detailed derivation of the model is given in Appendix A. The final relationship between the volume fraction of the phase, $V f$, and the area fraction measured from the overlapping particles in the TEM micrograph, $A f$, is given by

$$
V f=1-(1-A f) m
$$

where the exponent, $m=4.32 R 3 h+4.32 R$, is defined by the thickness of the TEM film, $h$, and the mean radius of the spherical particles, $R$.

Careful determination of the exponent $m$ is required for accurate interpretation of the results. The thickness of carbon film was measured using atomic force microscopy. The diameter of $\gamma^{\prime}$ precipitates was determined from the average value of a minimum of 200 particles measured using enough bright field (BF) TEM micrographs (20 in the present case) per exposed sample in order to minimize the statistical variance of the measurements. The standard error in the measurement was in the range from $0.1-2.4 \%$. The measured diameter, defined as 2RextTEM, is related to the mean particle radius, $R$, by eqn (A.9). The estimation of the volume fraction $\gamma^{\prime}$ particles was then conducted using equation (1).

\section{Measurement of Dislocation Density}

The dislocation structures observed in the thin foils are assumed to be approximately representative of the bulk material. The dislocation densities were obtained from individual TEM micrographs following the standard procedure. ${ }^{[25-28]}$ Each dislocation density measurement was based on a number of micrographs, from different areas of the foil, taken at magnifications from 7,000 to 12,000 . (With the $923 \mathrm{~K}\left(650^{\circ} \mathrm{C}\right) 574$ hours sample the number of micrographs was smaller 
as it was particularly difficult to obtain a thin foil with electron transparent regions). These magnifications were high enough to resolve the individual dislocations.

The dislocation density $(\rho d)$ measurement of randomly oriented dislocations, as shown by $\operatorname{Ham}^{[27]}$ and Hirsch et al. ${ }^{[28]}$, in units of $\mathrm{m} / \mathrm{m}^{3}\left(\right.$ lines $\left./ \mathrm{m}^{2}\right)$, was obtained from:

$$
\rho d=2 N M k L t
$$

where $N$ is the number of intersections that a random circle laid on a transmission electron micrograph makes with the dislocations, $L$ is the total circumference of the test circles, $M$ is the magnification of the micrograph, $t$ is the foil thickness and $k$ accounts for the number of dislocations which are not visible in the image for two-beam diffraction conditions; for the $\{110\}$ reflection used throughout, $k=$ $65 .{ }^{[26]}$ The dislocation intersections were counted using a series of circles to minimize any dislocation orientation effects. Six concentric circles from $5.7 \mathrm{~cm}$ to $18.5 \mathrm{~cm}$ in circumference were used.

The foil thickness was determined by counting extinction contours imaged under two-beam contrast condition. ${ }^{[28]}$ During imaging, two-beam conditions are used to optimise contrast. The foil thickness $(t)$ was measured using:

$$
t=\eta_{g} \xi_{g}
$$

where $\eta_{g}$ is the number of extinction fringes observed at an inclined boundary when the diffracted beam is represented by the reciprocal lattice vector $g$ and the term $\xi_{g}$ is the extinction distance for that $\boldsymbol{g}$ vector and accelerating voltage. The extinction distance $\xi_{g}(\AA)$ in nickel for $200 \mathrm{kV}$ electron accelerating voltage at reflection $\boldsymbol{g}=\left\langle 110>\right.$ was used in the measurement. ${ }^{[28]}$

\section{Thermodynamic Prediction}

The composition and volume fraction of the different equilibrium precipitate phases in Inconel 617 alloy were computationally predicted using the thermodynamic calculation programs JMatPro $^{[29]}$ and Thermo-Calc with the Ni-DATA database (version 7), supplied by the company Thermo-Calc Software. ${ }^{[30]}$ The inputs to the calculation were the alloy composition and temperature. The calculations carried out here focus on the interrelationship between $\gamma^{\prime}$ and nitrogen content.

\section{Characterisation of TiN Particles}

The microstructural characterisation carried out here concentrated on the TiN content as this interrelates with the thermodynamic prediction of the interchange between $\gamma^{\prime}$ and nitrogen content (and hence TiN). Crept specimens were prepared for metallography by the method described earlier. The standard polishing technique was to grind with successively finer grades of SiC emery papers and diamond suspensions to prepare specimens for metallography. Scanning electron microscopy (SEM) was performed on specimens in the polished but unetched conditions, in both secondary electron (SE) and backscattered electron (BSE) imaging modes. Energy dispersive X-ray (EDX) analysis enabled elemental compositions of phases to be ascertained using a Princeton Gamma Tech (PGT, NJ, USA) system attached to a FEI SIRION 200 Model FEG-SEM. The average area fraction of TiN particles over a number of SEM micrographs was determined for the $923 \mathrm{~K}\left(650^{\circ} \mathrm{C}\right) / 574$ hours sample, as an exemplar. The area fraction is indicative of the volume fraction as the TiN particles tend to be 
equiaxed (and given the sparsity of the particles the error is large making any stereological correction redundant). The error quoted in the results below is a statistical error based on the range of area fraction measurements. The regions examined were: edge of head; centre of head; edge of gauge length; centre of gauge length.

For the $923 \mathrm{~K}\left(650^{\circ} \mathrm{C}\right) / 574$ hours sample, carbon replicas were also examined by TEM for the presence of TiN particles at high magnifications.

\section{RESULTS}

\section{Metallography and Vickers Hardness Measurements}

Fig. 4 shows optical micrographs of longitudinal sections through the gauge length for each of the creep exposed samples, highlighting the existence of creep cracks penetrating into the gauge length from the surface. The plot of hardness versus Larson-Miller parameter for the creep-exposed samples is shown in Fig. 5. The Larson-Miller (LM) parameter was calculated using the relationship:

$$
L M=T\left[\frac{C_{L M}+\log t_{r}}{1000}\right]
$$

where $T$ is the absolute temperature, $C_{L M}$ is 20 and independent of the material, and $t_{r}$ is rupture time in hours. The error bars in the plot show the $90 \%$ confidence limits.

\section{Gamma Prime Observation using TEM}

Figures 6-9 are typical bright field (BF) TEM micrographs of $\gamma^{\prime}$ precipitates from carbon replicas with an inset indexed selected area electron diffraction pattern (SAEDP) from the $\gamma^{\prime}$. For volume fraction estimation, the thickness of the carbon film was in the range of 16-200nm (see Table 2). There is a large variation in the film thickness as it is difficult to control the film thickness in the extraction replica technique and it depends on many factors. The results are shown in Table 2, along with the average particle diameter. The exponent $<\boldsymbol{m}<\mathbf{1}$ is indicative of the amount of expected particle overlap in the image, with $\boldsymbol{m}=$ corresponding to no overlap (very thin film) and $\boldsymbol{m}=$ corresponding to $100 \%$ overlap (very thick film). The smallest value of $\boldsymbol{m}=$. is for the $923 \mathrm{~K}$ $\left(650^{\circ} \mathrm{C}\right) / 45,000$ hours case. This is by far the thickest film (in relation to particle size) and hence significant amounts of overlap are expected. This is supported by Figure 8 in which particle overlap is clearly observed.

The precipitates were nearly spheroidal and the size ranges and average sizes are given in Table 3. It should be noted that for the as-received sample it was difficult to extract $\gamma^{\prime}$ precipitates from the matrix, due to the sparse distribution of precipitates. The sample in Fig. 7 is, at 16nm, the thinnest TEM replica, and hence little overlap of the particles is expected to be observed. In contrast, that in Fig. 8 is the thickest TEM replica $(200 \mathrm{~nm})$, roughly 5 times the particle diameter. Therefore significant overlap between particles can be observed, as well as enhanced contrast between particles at different depths, as indicated by the particle coloration varying from dark grey to almost white. 


\section{Estimation of Dislocation Density using TEM Thin Film Micrographs}

Figures 10-13 are thin film TEM micrographs showing arrays of dislocations and piling-up around the precipitates. The blocky particles are $\mathrm{M}_{23} \mathrm{C}_{6}$ carbides. The estimated average dislocation densities are summarised in Table 3 . The results are an order of magnitude higher for the creepexposed samples than for the as-received. The interaction of precipitates with dislocations is marked with arrows in Fig. 12.

\section{Summary of Microstructural Information, Hardness and Larson-Miller Parameters}

Table 3 summarises the microstructural information on the as-received and creep-exposed Inconel 617 for:- diameter of $\gamma^{\prime}$ precipitates; grain sizes and morphology; $\gamma^{\prime}$ volume fractions; average Vickers hardness in the head and gauge length of samples; Larson-Miller parameter; and dislocation density.

\section{Thermodynamic prediction}

The volume fractions of $\gamma^{\prime}$ and TiN are linked through the nitrogen concentration. It is found that TiN is thermodynamically preferred over $\gamma^{\prime}$, and will form to absorb all the nitrogen available. The $\gamma^{\prime}$ will form from the remaining $\mathrm{Ti}$, with roughly equal quantities of $\mathrm{Al}$ (mol \%). Any excess $\mathrm{Al}$ remains in the matrix. Hence it is useful to consider the data for $\gamma^{\prime}$ and TiN together. The thermodynamic predictions for the variation in the volume fraction of both phases are shown in Figure 14. It is clear that the nitrogen content of the material is important. The value given in the specification in Table 1 is $0.004 \mathrm{wt} \%$ although, unlike the other elements, this composition is not well-controlled during the manufacturing process. This would render the TiN fraction negligible, with a maximum $\gamma^{\prime}$ fraction of $6.8 \mathrm{vol} \%$.

\section{Characterisation of TiN Particles}

Fig. 15 is for the $923 \mathrm{~K}\left(650^{\circ} \mathrm{C}\right) / 574$ hours sample and shows additional TiN precipitates in the gauge length in comparison with the head and also the enhancement towards the edge of the sample in comparison with the centre. The volume fractions measured by image analysis are: $0.03 \%$ for the edge of the gauge length in comparison with $0.02 \%$ for the centre and $0.001 \%$ for the edge of the head in comparison with $0.004 \%$ for the centre. These figures are a reflection of the fact that there are few TiN particles and they are sparsely distributed; the error is consequently large but there is clearly an order of magnitude difference between the gauge length and the head.

A typical TEM carbon replica image of the guage length of the same sample (i.e. 923K $\left(650^{\circ} \mathrm{C}\right) / 574$ hours $)$ is shown in Fig. 16. Particles have been analysed by SAEDP. A number of TiN particles (with the distinctive cuboidal morphology) are shown in the image. Further work would be needed to obtain a fully representative area fraction value (and hence to deduce a volume fraction). However, it is clear that there is a distribution of tiny TiN particles in the microstructure and therefore the volume fraction will be higher than that deduced from the FEGSEM images. 


\section{Comparison between Experimentally Observed Volume Fractions for Gamma Prime and TiN with the ThermoCalc Predictions}

Fig. 17 integrates the experimentally observed volume fractions for $\gamma^{\prime}$ with the ThermoCalc predictions. The $\gamma^{\prime}$ in the as-received matches reasonably well with the equilibrium predictions, given that with the as-received there is a $943 \mathrm{~K}\left(670^{\circ} \mathrm{C}\right), 10$ hour heat treatment, so the point should be roughly half way between the horizontal lines, although slightly below is expected as all the $\gamma^{\prime}$ would not precipitate out in 10 hours. With the creep exposure the volume fraction of $\gamma^{\prime}$ is at a lower value. If we then cross-reference to Fig. 14 with the experimentally observed $\gamma^{\prime}$ volume fractions, for a volume fraction of $\sim 2.9 \% \gamma^{\prime}$, for example, we would expect a TiN volume fraction of $\sim 0.7 \%$. For 3.2 and $3.4 \%$ volume fraction $\gamma^{\prime}$, we would expect a slightly lower TiN volume fraction of $\sim 0.6 \%$. There is an issue here because the area (volume) fractions from the SEM characterisation (cf. Fig. 15) are at least an order of magnitude smaller than the values here. This might suggest that the bulk of the TiN particles may not be visible in the SEM because their size is below the resolution. The evidence to support this is typified in Fig. 16 but an extensive further study would be required to obtain a reliable and fully representative volume fraction from such images.

\section{DISCUSSION}

Considering first the hardness results in Figure 5, the hardness in the gauge length for the creep exposed specimens is significantly higher than that in the head, which it can be assumed has received only thermal exposure with no creep strain. In addition, the creep exposed specimens have higher hardness than the as-received. The grain size is relatively constant for all samples (see Table 3). The higher hardness in the head relative to the as-received is likely to be due to the dislocations generated by the hardness test interacting with precipitate structures (both carbides and $\gamma^{\prime}$ ) and with solid solution hardening elements. The typical precipitate diameter for optimum resistance to both cutting and bowing of dislocation is 3-60 $\mathrm{nm}$. 'A critical diameter for cutting and bowing the dislocation can be determined using the following equation: $\mathrm{Dc}=4 \pi \mathrm{GmbGp}$; where $\mathrm{Gm}$ and $\mathrm{Gp}$ represent the shear modulus of the matrix and the precipitates respectively. ${ }^{[31]}$ Following are the data used for determining the critical diameter of gamma prime precipitates in the temperature range of $923 \mathrm{~K}$ to $973 \mathrm{~K}\left(650\right.$ to $\left.700^{\circ} \mathrm{C}\right)$ :

$$
\begin{aligned}
& \mathrm{Gm}=65 \mathrm{GPa}^{[32]} \\
& \mathrm{Gp}=70 \mathrm{GPa}^{[33]} \\
& \mathrm{b}=\mathrm{a} 2<110>
\end{aligned}
$$

$\mathrm{b}=0.361212+12+0=0.255 \mathrm{~nm}$

The upper bound of $60 \mathrm{~nm}$ is an estimate based on the inverse relationship between the strength due to dislocation bowing and the particle diameter. 
The $\gamma^{\prime}$ particle sizes are in this range (Table 4 summarises the data from the literature in comparison with the data obtained in this work) whilst the carbides tend to be bigger (e.g. see Fig. $10)$.

For the gauge length, we can consider the relationship between the measured dislocation densities and the hardness values. ${ }^{[34]}$ The relationship between the initial yield stress of a material, , and its yield stress after work hardening, can be expressed as

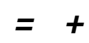

(5)

where is a geometric parameter (typically around 0.1 to 1 ), is the shear modulus, is the magnitude of the Burgers vector and is the dislocation density. The Vickers hardness, , can be related to the tensile strength, , of the material through the relationship

where $\approx 3$ if the tensile stress is in MPa. Given that the tensile strength of IN617 is typically 2-2.5 times the yield stress, this suggest that a change in hardness of the material due to work hardening can be estimated from

$\Delta=$

where $\delta \sim 2.5 \alpha \beta \sim \alpha$ is of the order of 0.1 to 1.0. The change in hardness due to work hardening is assumed to be the difference between the hardness in the gauge length and the hardness in the head. This relationship between the square root of the dislocation density and the change in hardness is shown in Figure 18. Taking $G=81 \mathrm{GPa}$ and $b=0.25 \mathrm{~nm},{ }^{[32]}$ the linear fit shown is for a fitting parameter of $\delta=0.8$, which is within the estimated physical range for this parameter. The data is quite scattered, but the fit demonstrates that the relationship holds reasonably well, to within a factor of 1.5 , with $\delta=0.6-1.2$ covering the entire range of results (including error bars). The error bars are based on the data in Table 3 .

Whilst it is difficult to strongly argue for a particular trend from three data points, the relation between dislocation density and hardness is quite widely accepted so it seems sensible to test this correlation. There is considerable scatter in the data (hence the error bars) but the line fits through all the points within the known margin of error. The fact that the point with the highest dislocation density has only the second highest hardness value is not inconsistent with the accuracy of the data. There is intrinsic scatter in all these values as hardness and dislocation density will naturally vary for each location inspected.

This supports the proposal that the increase in the hardness in the head region is due to precipitate hardening, and that in the gauge region is due to work hardening plus precipitate hardening.

The sample exposed at $923 \mathrm{~K}\left(650^{\circ} \mathrm{C}\right)$ for $45,000 \mathrm{~h}$ has shown an average Vickers hardness of $353 \mathrm{Hv} / 20$. For the higher temperature but shorter time $\left(973 \mathrm{~K}\left(700^{\circ} \mathrm{C}\right)\right.$ for $\left.4,000 \mathrm{~h}\right)$ the average 
Vickers hardness value is slightly lower (343Hv/20) which may be attributed to dynamic recovery at the higher temperature.

$\mathrm{Wu}$ et al.$^{[15]}$ reported that for samples aged at temperatures of $811 \mathrm{~K}\left(538^{\circ} \mathrm{C}\right), 866 \mathrm{~K}\left(593^{\circ} \mathrm{C}\right)$ and $977 \mathrm{~K}\left(704^{\circ} \mathrm{C}\right)$ for durations of 19,830 hours, 21,482 hours and 65,600 hours, the microhardnesses were 193, 262 and $209 \mathrm{Hv}$ respectively. Mankins et al. ${ }^{[8]}$ observed a small amount of $\gamma^{\prime}$ particles of type $\mathrm{Ni}_{3} \mathrm{Al}$ precipitated in Inconel 617 alloy after creep exposure at $1033 \mathrm{~K}\left(760^{\circ} \mathrm{C}\right)$ for more than $10,000 \mathrm{~h}$ and the hardness value was $192 \mathrm{Hv}$ along the gauge length. Again this hardness value is lower than those observed here. They reported that the amount of $\gamma^{\prime}$ precipitates was not sufficient to cause appreciable hardening but did contribute to some strengthening at temperature of $922 \mathrm{~K}\left(649^{\circ} \mathrm{C}\right)$ to $1033 \mathrm{~K}\left(760^{\circ} \mathrm{C}\right)$. These hardness values are much lower than those observed with the creep-exposed samples in the present study. The enhancement in hardness here over the as-received samples is attributed to the simultaneous effect of temperature and mechanical strain during the creep deformation process, leading to precipitate development and work hardening. It is not clear how the differences in hardness between this and previous work can be resolved, although the TiN partciles visible at high magnification e.g. in Fig. 16 may be contributing.

The $\gamma^{\prime}$ sizes observed here are consistent with those in the literature and are relatively stable with creep exposure. There is evidence from Table 4 that at higher temperatures and times (creep at $1073 \mathrm{~K}\left(800^{\circ} \mathrm{C}\right), 34,000 \mathrm{~h}{ }^{[14]}$ and thermal exposure at $\left.977 \mathrm{~K}\left(704^{\circ} \mathrm{C}\right), 65,600 \mathrm{~h}^{[15]}\right)$ significant coarsening of the $\gamma^{\prime}$ does occur to about $200 \mathrm{~nm}$ diameter.

The volume fraction of $\gamma^{\prime}$ decreases between the as-received sample $(5.8 \pm 0.6 \mathrm{vol} \%)$ and the sample creep exposed at $923 \mathrm{~K}\left(650^{\circ} \mathrm{C}\right)$ for $574 \mathrm{~h}(2.9 \pm 0.6 \mathrm{vol} \%)$. The values for the creep exposed samples are all then quite similar (Table 4 ) and could be the same given the bounds of experimental error. They are comparable with those obtained by Penkalla et al. ${ }^{[13]}$ and Wu et al.$^{[15]}$ for thermally exposed samples but significantly higher than that reported by Mankins et al. ${ }^{[8]}$ The previous papers do not discuss the role of nitrogen content in influencing the $\gamma^{\prime}$ volume fraction. Fig. 14 shows that as the nitrogen content increases the fraction of $\mathrm{TiN}$ increases and the gamma prime fraction decreases.

The volume fraction of $\gamma^{\prime}$ in the as-received alloy (about 5.8\%) is roughly consistent (see section on 'Comparison between Experimentally Observed Volume Fractions for Gamma Prime and TiN with the ThermoCalc Predictions') with the predicted equilibrium volume fraction at the heat treatment temperature of $943 \mathrm{~K}\left(670^{\circ} \mathrm{C}\right)$ for the nominal $\mathrm{N}$ content of $0.004 \mathrm{wt} \%$ (Table 1). With creep exposure the volume fraction of $\gamma^{\prime}$ drops to around 3\%. According to Fig. 14 this would indicate a TiN volume fraction of between 0.6 and $0.7 \%$ and a nitrogen content of just over $0.1 \mathrm{wt} \%$. The only potential source of nitrogen is the atmosphere and therefore the question arises as to whether nitrogen is penetrating into the sample during the creep test. Fig. 4 shows extensive creep cracks penetrating into the sample from the surface of the gauge length and hence providing an access route for the nitrogen. The finding from SEM that the volume fraction of TiN is higher at the edge of the gauge length $(0.03 \%)$ than in the centre $(0.02 \%)$ supports this argument but the order of magnitude is incorrect. This could, as mentioned earlier, occur because those experimental observations are via SEM and very small TiN particle may not be being observed. The TEM carbon replica images (e.g. Fig. 16) support the argument that the actual volume fraction of TiN is higher than indicated by the FEGSEM images (e.g. Fig. 15). There is also a difference in the SEM images between the TiN volume fraction in the centre of the gauge length $(0.02 \%)$ and that in the centre of the head $(0.004 \%)$ which suggests that nitrogen is penetrating to the centre of the gauge length during the test. This effect is not expected to be observed in real components which are much larger and operate in different 
atmospheres. The interrelationship between $\gamma^{\prime}$ and nitrogen content may however be relevant to experimental observations with creep samples in the literature.

To analyse the possibility of the diffusion of nitrogen further the following analysis can be carried out. The diffusion coefficient for $\mathrm{N}$ in Ni-20Cr-2Ti (which is fairly close to IN617) is estimated by Krupp and Christ ${ }^{[35]}$ from the movement of a nitridation front at $1173 \mathrm{~K}$ to $1373 \mathrm{~K}\left(900-1100^{\circ} \mathrm{C}\right)$ to be

$D N(T)=4.7 \times 10-6 \exp -126 \times 103 R T \mathrm{~m} 2 / \mathrm{s}$

This gives

$D N 650 \circ C=3.48 \times 10-13 \mathrm{~m} 2 / \mathrm{s}$

$D N 700 \circ C=8.08 \times 10-13 \mathrm{~m} 2 / \mathrm{s}$

Yuan et al. ${ }^{[36]}$ quote the penetration depth of the nitridation zone (where TiN is found) as $\xi=2 c N D N t c T i$

where $c N$ and $c T i$ are the atomic concentrations of $\mathrm{N}$ and Ti respectively and $t$ is time. This expression assumes that all the $\mathrm{N}$ is used to form $\mathrm{TiN}$ as it moves into the matrix (i.e. a very distinct layer), and hence the $\mathrm{N}$ continually needs to be replenished from the surface for nitridation to continue. At temperatures greater than $1173 \mathrm{~K}\left(900^{\circ} \mathrm{C}\right)$, Krupp and Christ ${ }^{[35]}$ see a very clear oxide layer and a very clear layer of high density TiN formation. They have a Ti concentration of $c T i=4.88$ at $\%$ in their alloys, which equates to about $8-9 \mathrm{vol} \% \mathrm{TiN}$ in the nitride layer. They calculate that the maximum solubility of $\mathrm{N}$ in $\mathrm{Ni}$ at $950^{\circ} \mathrm{C}$ is $c N=0.0018 \mathrm{at} \%$. This reduces even further with temperature, with extrapolation indicating $c N \approx 0.00001$ at $\%$ at $923-973 \mathrm{~K}\left(650-700^{\circ} \mathrm{C}\right)$.

Yuan et al.$^{[36]}$ calculate a penetration depth of 188 microns at $1223 \mathrm{~K}\left(950^{\circ} \mathrm{C}\right)$ after $680 \mathrm{~h}$, but observe a depth nearer to $30-40$ microns (the theoretical result assumes nitrogen ingress is unimpeded by oxide layer).

Here we have a smaller Ti fraction, with $c T i=0.6$ at $\%$ which slightly increases the penetration depth, but the lower temperatures and lower $c N$ decrease it. This gives an upper bound of $\xi=100$ microns at $923 \mathrm{~K}\left(650^{\circ} \mathrm{C}\right)$ after 574 hours, $\xi=885$ microns at $923 \mathrm{~K}\left(650^{\circ} \mathrm{C}\right)$ after 45,000 hours and $\xi=393$ microns at $973 \mathrm{~K}\left(700^{\circ} \mathrm{C}\right)$ after 4000 hours.

If we then compare with the observations, in this work we see TiN fractions of $0.03 \mathrm{vol} \%$ (edge) and $0.02 \%$ (centre) in the gauge length and smaller values in the head $(0.001 \%-0.004 \%)$ in the $923 \mathrm{~K}$ $\left(650^{\circ} \mathrm{C}\right) 574 \mathrm{~h}$ sample which has a radius of $3 \mathrm{~mm}$. The nitridation layer model above predicts that we will see an ever thickening layer of nitrides with $1 \mathrm{vol} \%$ TiN but this is not what is found. This suggests that the $\mathrm{N}$ is ingressing through the matrix without rapidly interacting with the gamma prime to form TiN (in contrast with Krupp and Christ ${ }^{[35]}$ and with Yuan et al. ${ }^{[36]}$ ). This seems plausible at the lower temperature, such that it takes time for dissolution of the gamma prime to release the Ti for TiN formation, and hence the $\mathrm{N}$ can progress further into the body without being absorbed. If the diffusing species does not interact with its environment then the characteristic diffusion distance is roughly 
with $\mathrm{N}$ roughly at $50 \%$ of the surface concentration at this distance, dropping to $20 \%$ at $2 \mathrm{~L}$ and $5 \%$ at $3 \mathrm{~L}$. At $923 \mathrm{~K}\left(650^{\circ} \mathrm{C}\right)$ after 574 hours this distance is $L=1.3 \mathrm{~mm}$. Taking into account the cylindrical geometry, the penetration distance will be slightly larger, so there will be some $\mathrm{N}$ diffusion as far as the centre of the sample. It is, thus, possible to argue that $\mathrm{N}$ penetrates through the $574 \mathrm{~h}$ sample in the time available assuming there is no intact oxide scale to inhibit $\mathrm{N}$ ingress. Indeed the penetration process will be aided by the extensive creep cracks that are observed.

Given the role of $\gamma^{\prime}$ in contributing some precipitation hardening and creep strength during long term exposure it is important to be conscious of the potential role of nitrogen in determining the $\gamma^{\prime}$ precipitate content in creep specimens and the fact that this may differ from real components.

\section{CONCLUDING REMARKS}

1) $\gamma^{\prime}$ precipitates were randomly distributed, fine, approximately spheroidal in shape, and resistant to morphology change. They were observed in all exposure conditions and were spheroidal in morphology. There is an increase in size from an average of $18 \mathrm{~nm}$ diameter to an average of $30 \mathrm{~nm}$ diameter in the early stages of creep exposure at $923 \mathrm{~K}\left(650^{\circ} \mathrm{C}\right)$ with relatively little growth with a further 45,000 hours at this temperature. At $973 \mathrm{~K}\left(700^{\circ} \mathrm{C}\right), 4000$ hours the size was similar.

2) The volume fraction of $\gamma^{\prime}$ was observed to decrease between the as-received condition (5.8 vol $\%)$ and the creep exposed condition ( $\sim 3 \mathrm{vol} \%)$. Thermodynamically an interrelationship is predicted between the volume fraction of $\gamma^{\prime}$ and that of TiN with the TiN forming in preference to $\gamma^{\prime}$ in terms of the available $\mathrm{N}$ content. This interrelationship has not previously been commented on in the literature. There is some evidence that nitrogen is penetrating into the creep sample from the atmosphere and affecting results. Experimentalists should be cogniscent of this potential effect. The effect is not expected in industrial components which are much larger and operate in different atmospheres.

3) The hardness is higher in the creep exposed samples than in the as-received, with the gauge length (subjected to creep stress) significantly higher than the head of the creep specimen (no creep stress). There is some indication that this latter finding may be associated with work hardening.

4) The dislocation density in the as-received sample was approximately $3.5 \times 10^{13}$ lines $/ \mathrm{m}^{2}$ and in the creep exposed samples for $923 \mathrm{~K}\left(650^{\circ} \mathrm{C}\right), 574$ hours, $5.0 \times 10^{14} \mathrm{lines} / \mathrm{m}^{2}$, for $923 \mathrm{~K}$ $\left(650^{\circ} \mathrm{C}\right), 45,000$ hours, $5.93 \times 10^{14}$ lines $/ \mathrm{m}^{2}$ and for $973 \mathrm{~K}\left(700^{\circ} \mathrm{C}\right), 4000$ hours, $3.5 \times 10^{14}$ lines $/ \mathrm{m}^{2}$. There is no previous data in the literature for dislocation densities under these conditions

\section{ACKNOWLEDGEMENTS}


The authors would like to thank ALSTOM Power Ltd. for supplying creep-exposed Inconel 617 alloys and wish to thank the UK Government's Technology Strategy Board for providing financial support to carry out this work. Mr G. Clark is thanked for help with microscopy and preparing samples for TEM analysis. Dr R. Chantry is thanked for assistance with dislocation density analysis. Prof A Strang and Dr G McColvin have provided valuable advice and guidance.

\section{REFERENCES}

1. J.C. Hosier, and D.J. Tillack: INCONEL alloy 617 - A new high temperature alloy, Metals Engineering Quarterly, 1972, vol. 12 (3), pp. 51-55.

2. R.W. Vanstone: Advanced $700^{\circ} \mathrm{C}$ pulverized fuel power plant, Proc. 5th International Charles Parsons Turbine Conference: Parsons 2000: Advanced Materials for $21^{\text {st }}$ Century Turbine and Power Plants, eds.: A. Strang, W. M. Banks, R. D. Conroy, G. M. McColvin, J. C. Neal and S. Simpson, IOM Communications, Ltd., London, 2000, 736, pp. 91-97.

3. F. Masuyama: History of power plants and progress in heat-resistant steels, ISIJ International, 2001, vol. 41(6), pp. 612-625.

4. R. Viswanathan, J. F. Henry, J. Tanzosh, G. Stanko, J. Shingledecker, B. Vitalis and R. Purgert: U.S. Program on Materials Technology for Ultra-Supercritical Coal Power Plants, Journal of Materials Engineering and Performance, 2005, vol. 14(3), pp.281-292.

5. S. Chomette, J.-M. Gentzbittel and B. Viguier, J. Nuclear Materials, 2010, vol. 399, pp. 266274.

6. D. Kaoumi and K. Hrutkay, J. Nuclear Materials, 2014, vol.454, pp. 265-273.

7. A.K. Roy, M.H. Hasan and J. Pal, Mater. Sci. and Engng. A, 2009, vol. A520, pp. 184-188.

8. W.L. Mankins, J.C. Hosier, and T.H. Bassford: Microstructure and phase stability of INCONEL alloy 617. Metall. Mater. Trans. B 1974, vol. 5, pp. 2579-2590.

9. Y. Hosoi, and S. Abe: The Effect of Helium Environment on Creep Rupture Properties of Inconel 617 at $1000^{\circ} \mathrm{C}$, Metall. Trans. A 1975, vol. 6A, pp. 1171-1178.

10. S. Kihara, J.B. Newkirk, A. Ohtomo, Y. Saiga: Morphological changes of carbides during creep and their effects on the creep properties of Inconel 617 at $1000^{\circ} \mathrm{C}$, Metall. Trans. A, 1980, vol. 11A, pp. 1019-1031. 
11. R. Krishna, S.V. Hainsworth, H.V. Atkinson and A. Strang: Materials Science and Technology, 2010, vol. 26(7), pp. 797-802.

12. S. Chandra, R. Cotgrove, S.R. Holdsworth, M. Schwienheer and M.W. Spindler: in Proc. ECCC Creep Conf. on Creep and Fracture in High Temperature Components-Design and Life Assessment Issues, I.A. Shibli, S.R. Holdsworth and G. Merckling eds., DEStech Publications, London, and Lancaster PA, 2005, 178-188.

13. H.-J. Penkalla, J. Wosik, E.V. Fischer, F. Schubert: Structural investigations of candidate materials for turbine disc applications beyond 700 degrees Celsius, Proc. $5^{\text {th }}$ International Symposium on Superalloys 718, 625, 706, and Derivatives,eds. E.A. Loria, 17-20 June 2001, Pittburgh, Pennsylvania pp. $279-290$.

14. E. Gariboldi, M. Cabibbo, S. Spigarelli and D. Ripamonti: International Journal of Pressure Vessels and Piping, 2008, vol. 85, pp. 63-71.

15. Q. Wu, H. Song, R.W. Swindeman, J.P. Shingledecker, and V.K. Vasudevan: Metallurgical and Materials Transactions A, 2008, vol. 39A, pp. 2569-2585.

16. O.F. Kimball, G.Y. Lai, and G.H. Reynolds: Effects of thermal aging on the microstructure and mechanical properties of a commercial Ni-Cr-Co-Mo alloy (Inconel 617), Metallurgical and Materials Transactions A, 1976, vol.7A, pp. 1951-1952.

17. T. Takahashi, J. Fujiwara, T. Matsushima, M. Kiyokawa, I. Morimoto, and T. Watanabe, Analysis of precipitated phase in heat treated INCONEL alloy 617, Trans. ISIJ, 1978, vol. 18 pp. 221-224.

18. H. Kirchhöfer, F. Schubert, and H. Nickel: Precipitation behavior of Ni-Cr-22 Fe-18 Mo (Hastelloy-X) and Ni-Cr-22 Co-12 Mo (Inconel 617) after isothermal aging, Nucl. Technol., 1984, vol. 66 (1), 139-148.

19. K.R. Vishwakarma, N.L. Richards and M.C. Chaturvedi: Materials Science and Engineering A, 2008, vol. 480 (1-2), pp. 517-528.

20. R. Krishna, S.V. Hainsworth, S.P.A. Gill, A. Strang, and H.V. Atkinson: Metallurgical and Materials Transactions A, 2013, vol. 44A, pp. 1419-1429. 
21. R. Krishna, S. V. Hainsworth, S.P.A. Gill, A. Strang and H. V. Atkinson: Proc. $2^{\text {nd }}$ Int. ECCC Conf. on 'Creep \& fracture in high temperature components - Design \& Life assessment' eds. I.A. Shibli and S.R. Holdsworth, 21-23 April 2009, Zurich, pp. 764-776.

22. P.J. Ennis and W.J. Quadakkers: in Proc. 7th Int. Charles Parson Turbine Conf. on Power Generation in an Era of Climate Change, A. Strang, W.M. Banks, G.M. McColvin, J.E. Oakey and R.W. Vanstone eds., Institute of Materials, London, 2007, 509-518.

23. M. Avrami: Journal of Chemical Physics, 1941, vol. 9 (2), pp.177-184.

24. W. Johnson and R. Mehl: Trans. Am. Inst. Min. Metall. Eng. 1939, vol. 135, pp. 416-458.

25. J.R. Yang and H.K.D.H. Bhadeshia: Welding Journal Research Supplement, 1990, vol. 69, $305 \mathrm{~s}-307 \mathrm{~s}$.

26. R. Hambleton, W.M. Rainforth and H. Jones: Philosophical Magazine A, 1997, vol. 76 (5), pp. 1093-1104.

27. R.K. Ham: Phil. Mag., 1961, vol. 6, pp. 1183-1184.

28. P. Hirsch, P. Howie, R.B. Nicholson, D.W. Pashley and M.J. Whelan, Electron Microscopy of Thin Crystals, Krieger, New York, N.Y. 1977.

29. N. Saunders, Z. Guo, X. Li, A.P. Miodownik, and J.-P. Schillé: in Superalloys 2004, K.A. Green, T.M. Pollock, and H. Harada, eds.,TMS (The Minerals, Metals \& Materials Society), Warrendale, PA, 2004, pp. 849-58.

30. Thermo-Calc Software AB (Version 4), http://www.thermocalc.com, SE-113 47: Stockholm, Sweden, August 2006.

31. C.P. Blankenship Jr, E. Hornbogen, and E.A. Starke Jr, Materials Science and Engineering A, 1993, vol. 169A, pp. 33-41.

32. Inconel alloy 617 datasheet, Publication Number SMC-029, Copyright $@$ Special Metals Corporation, 2005.

33. S.V. Prikhodko, H. Yang, A.J. Ardell, J.D. Carnes, and D.G. Isaak, Metallurgical and Materials Transactions A, 1999, vol.30A, pp. 2403-8.

34. W.D. Nix and H. Gao, J. Mech. Phys. Solids, 1998, vol. 46, pp. 411-25.

35. U. Krupp and H.J. Christ, Metall. Mater. Trans. A, 2000, vol. 31A, pp. 47-??? 
36. K. Yuan, R. Peng, X.H. Li, S. Johansson and Y. Wang, Simulation of oxidation-nitridationinduced microstructural degradation in a cracked Ni-based superalloy at high temperature. In MATEC Web of Conferences Vol. 14 (2014), EUROSUPERALLOYS 2014 - 2nd European Symposium on Superalloys and their Applications, Giens, France, May 12-16, 2014, Vol. 14, 16004. http://dx.doi.org/10.1051/matecconf/20141416004

37. J. Wosik, B. Dubiel, A. Kruka, H.-J. Penkalla, F. Schubert, A. Czyrska-Filemonowicz. Materials Characterization, 2001, vol. 46, pp. 119-123.

38. I.M. Lifshitz and V.V. Slyozov, J. Phys. Chem. Solids, 1961, vol. 19, pp. 35-50.

39. C. Wagner, Z. Elektrochem., 1961, vol. 65, pp. 581-591.

\section{APPENDIX A: Relationship between the projected area fraction of particles observed in the TEM micrograph and their actual volume fraction}

The observed area fraction of particles from a TEM micrograph depends on the thickness of the film, as the images of particles at different depths can overlap, as shown in Fig. 3(a). The effect of the overlap (or impingement) of particles imaged through a transparent film is very similar to those for a partially complete phase transformation. The classic Kolmogarov-Johnson-Mehl-Avrami (KJMA) equation ${ }^{[23,24]}$ considers the evolution of the volume fraction $V f$ of a phase as it grows over time. Taking into account the impingement of particles, this is expressed in terms of the extended volume fraction Vext, which is the volume fraction of particles that would exist in the absence of particle impingement. At any point in time, the fractional increase in the observed volume fraction, $d V f$, is given by the fractional increase in the extended volume fraction, $d V e x t$, multiplied by the probability that the new volume is not already transformed, $(1-V f)$, such that

$$
d V f=1-V f d V e x t
$$

This is readily integrated to give the widely used relationship

$$
V f=1-\exp (-V e x t)
$$

For small volume fractions the likelihood of impingement is small and the two volume fractions are approximately the same.

Now consider the projection of the three-dimensional (3D) transformed phase onto a two-dimensional (2D) plane, similar to that shown in Fig. 3(a). The increase in the observed volume fraction of the phase will be associated with an increase in the observed area fraction of the phase, $d A f$, in this plane. Similarly, the increase in the extended volume fraction of the transformed phase will be 
associated with an increase in the extended area fraction, Aext, in this plane. As before, the increase in the observed area fraction depends on the current untransformed area fraction, 1- $A f$, such that

$$
d A f=1-A f d A \operatorname{ext}
$$

and hence, similar to (1), we can also write

$$
A f=1-\exp (-A e x t)
$$

This applies to the 2D images of particles that we see in the transparent TEM images. Note that the particles do not typically impinge within the volume of the sample itself. The impingement here is simply the overlap of particles when imaged through the thickness of the sample. Clearly, the thicker the sample, the more overlap that is expected to be observed.

Now consider the situation in Figure 19, for a number of whole or partial spherical particles of radius $R$ in a film of thickness $h$. Within a central region of the sample, of thickness $h+2 R$, the particles are necessarily whole (uncut). Near the surface the particles are cut, and have centres that are within a distance of $\pm R$ of the specimen surface, as shown. The average volume of a particle subject to a single random cut at any point through its diameter is $23 \pi R 3$, half the volume of an intact particle. The extended volume fraction of the particles is therefore

$$
\text { Vext }=h-2 R h 43 \pi R 3+4 R h 23 \pi R 3 N=43 \pi N R 3
$$

where $N$ is the number of particles per unit volume. The extended volume fraction is independent of the sample thickness as expected. Similarly, the average cross-sectional area of a spherical particle cut on a random plane is $23 \pi R 2$. The projected cross-sectional area of a transparent particle is $23 \pi R 2$ if less than half the particle remains after the cut and $\pi R 2$ if more than half remains (as the maximum cross-section is observed). As each case is equally likely the average projected area is therefore $56 \pi R 2$. Thus the total extended area fraction of the particles cross-section is ${ }^{[37]}$

$$
\text { Aext }=h-2 R h \pi R 2+4 R h 56 \pi R 2 N h=3 h 4 R+1 V e x t .
$$

Rearranging (A.2) and (A.4), and substituting them in (A.6), we can express the actual volume fraction, $V f$, in terms of the observed area fraction in the TEM image, $A f$, as

$$
-\ln 1-A f=-3 h 4 R+1 \ln (1-V f)
$$

or finally

$$
V f=1-(1-A f) m
$$

where the exponent $m=4 R 4 R+3 h$. This expression is plotted in Figure 20 for a range of $m$ values. The linear relationship seen for small area fractions arises when there is negligible overlap. Note that this model is only strictly correct for $h>2 R$. For $h<2 R$ there is the possibility of a particle being cut twice by the film surface, both top and bottom. Taking this into account does slightly modify the exponent $m$, but not to such a significant extent that justifies the increase in complexity of the model. 
This analysis assumes all the particles are the same size. For a distribution of particle sizes, it can be shown that $R$ is replaced by $R 3 / R 2$, where $R 3$ is the average value of $R 3$ etc. For the Lifshitz, Slyozov and Wagner (LSW) particle size distribution ${ }^{[38,39]}$ for particles undergoing classic Oswald ripening, the relationships between area, volume and radius are $R 2=1.046 R 2$ and $R 3=1.13$ $R 3$. In this case, $R 3 / R 2=1.08 R$, so the exponent will be adjusted to $m=4.32 R 3 h+4.32 R$ for a typical distribution of particle sizes.

In addition, the quantity measured to characterise the particles size also needs to be considered carefully, so that what is actually measured on the micrograph is clearly interpreted. The average radius of a spherical particle of radius $R$ cut on a random plane is $\pi 4 R$. As before, for transparent particles the observed average radius is therefore $\pi 4 R$ if less than half the particle remains and $R$ if more than half remains. Hence the average observed radius for a cut particle is $121+\pi 4 R$. The average measured particle radius of all the cut and uncut particles of radius $R$ is therefore

$$
R e x t T E M=h-2 R h+2 R R+4 R h+2 R 12 \pi 4+1 R=h+1.57 R h+2 R R .
$$

This shows that the average cut radius varies from $0.785 R \leq \operatorname{RextTEM} \leq R$ as the film thickness goes from very small to very large. Taking the average value over a distribution of particle sizes gives $R=1.12 \operatorname{RextTEM}$, where $\operatorname{RextTEM}$ is the average particle radius measured from the TEM micrograph.

\section{Figure Caption List}

Figure 1:The geometry of the creep samples for the tests at (a) $923 \mathrm{~K}\left(650^{\circ} \mathrm{C}\right) / 45000 \mathrm{~h}$ and $973 \mathrm{~K}\left(700^{\circ} \mathrm{C}\right) / 4000 \mathrm{~h} ;(\mathrm{b}) 923 \mathrm{~K}\left(650^{\circ} \mathrm{C}\right) / 574 \mathrm{~h}$

Figure 2: Schematic diagram illustrating the regions where the TEM samples have been taken from and the locations of hardness measurements

Figure 3: Spherical particles observed in a thin film via TEM. (a) The particles are at different positions through the thickness of the film and hence appear to overlap in a TEM image. (b) The actual area of particles observed in the TEM image.

Figure 4: Optical micrographs montage showing the creep cracks penetrating into the gauge length (a) $923 \mathrm{~K}\left(650^{\circ} \mathrm{C}\right) / 574 \mathrm{~h},(\mathrm{~b}) 923 \mathrm{~K}\left(650^{\circ} \mathrm{C}\right) / 45000 \mathrm{~h}$ and (c) $973 \mathrm{~K}\left(700^{\circ} \mathrm{C}\right) / 4000 \mathrm{~h}$.

Figure 5: Vickers hardness versus LM parameter for creep-exposed Inconel 617 alloy at temperatures of $(923 \mathrm{~K}) 650^{\circ} \mathrm{C}$ and $973 \mathrm{~K}\left(700^{\circ} \mathrm{C}\right)$.

Figure 6: TEM micrograph showing the $\gamma^{\prime}$ precipitates, and indexed SAED pattern (inset) acquired from the $\gamma^{\prime}$ particles in the as-received sample. The beam direction was along [001]. 
Figure 7: (a) TEM micrograph showing the $\gamma^{\prime}$ precipitates in a carbon replica from a sample creep exposed at $923 \mathrm{~K}\left(650^{\circ} \mathrm{C}\right)$ for 574 hours under intermediate stress; (b) Indexed SAEDP of $\gamma^{\prime}$ precipitates. Beam direction and zone axis were along $\mathrm{B}=[001]$.

Figure 8: (a) TEM micrograph showing the $\gamma^{\prime}$ precipitates of spheroidal morphology in the sample creep exposed at $923 \mathrm{~K}\left(650^{\circ} \mathrm{C}\right)$ for $45,000 \mathrm{~h}$ under intermediate stress, and (b) SAEDP from $\gamma^{\prime}$ precipitates observed in (a). Beam direction and zone axis were along $\mathrm{B}=[001]$.

Figure 9: (a) TEM micrograph showing the spheroidal $\gamma^{\prime}$ precipitates uniformly distributed in the matrix of sample exposed at $973 \mathrm{~K}\left(700^{\circ} \mathrm{C}\right)$ for $4000 \mathrm{~h}$ under intermediate load, and (b) Indexed SAEDP from $\gamma^{\prime}$ precipitates from (a). The beam direction and zone axis were along $B=[011]$.

Figure 10: TEM micrograph illustrating dislocation structure, and dislocation-particle interactions in as-received sample.

Figure 11: TEM micrograph illustrating dislocation structure, and dislocation-precipitate interaction in austenitic $\gamma$-matrix in sample creep-exposed at $923 \mathrm{~K}\left(650^{\circ} \mathrm{C}\right)$ for $574 \mathrm{~h}$.

Figure 12: TEM micrograph for the sample creep-exposed at $923 \mathrm{~K}\left(650^{\circ} \mathrm{C}\right)$ for $45,000 \mathrm{~h}$ at intermediate stress. Precipitates in the micrograph are shown by arrow's heads.

Figure 13: TEM micrograph for sample creep-exposed at $973 \mathrm{~K}\left(700^{\circ} \mathrm{C}\right)$ for $4000 \mathrm{~h}$.

Figure 14: The variation in $\gamma^{\prime}$ and TiN volume percentage in IN617 with nitrogen content at $923 \mathrm{~K}\left(650^{\circ} \mathrm{C}\right)$ as predicted by ThermoCALC ${ }^{[30]}$.

Figure 15: SEM micrographs of (a) edge of gauge length, (b) centre of gauge length, (c) edge of the head and $(\mathrm{d})$ centre of the head of the sample $\left(923 \mathrm{~K}\left(650^{\circ} \mathrm{C}\right) / 574 \mathrm{H}\right)$; dark cuboidal precipitates are TiN particles.

Figure 16: TEM image from carbon replica of $923 \mathrm{~K}\left(650^{\circ} \mathrm{C}\right) / 574$ hours creep exposed sample showing precipitates identified as TiN and $\gamma^{\prime}$ by SAEDP.

Figure 17: A comparison between observed and thermodynamically predicted volume fractions (\%) at $923 \mathrm{~K}\left(650^{\circ} \mathrm{C}\right)$ and $973 \mathrm{~K}\left(700^{\circ} \mathrm{C}\right)$ for $\gamma^{\prime}$ precipitates.

Figure 18: The change in hardness due to work hardening versus square root of dislocation density (dislocation density in lines $/ \mathrm{m}^{2}$ ) showing a reasonably proportional relationship.

Figure 19: Cross-section through a thin film containing spherical particles. The centres of cut-particles exist within a distance of $\pm R$ of the sample surface giving it an effective thickness of $h+2 R$ in terms of the number of particles in the film.

Figure 20: The relationship between the measured area fraction from a TEM micrograph and the actual volume fraction. 


\section{Figures List}

Figure 1:The geometry of the creep samples for the tests at (a) $923 \mathrm{~K}\left(650^{\circ} \mathrm{C}\right) / 45000 \mathrm{~h}$ and $973 \mathrm{~K}\left(700^{\circ} \mathrm{C}\right) / 4000 \mathrm{~h}$; (b) $923 \mathrm{~K}\left(650^{\circ} \mathrm{C}\right) / 574 \mathrm{~h}$.

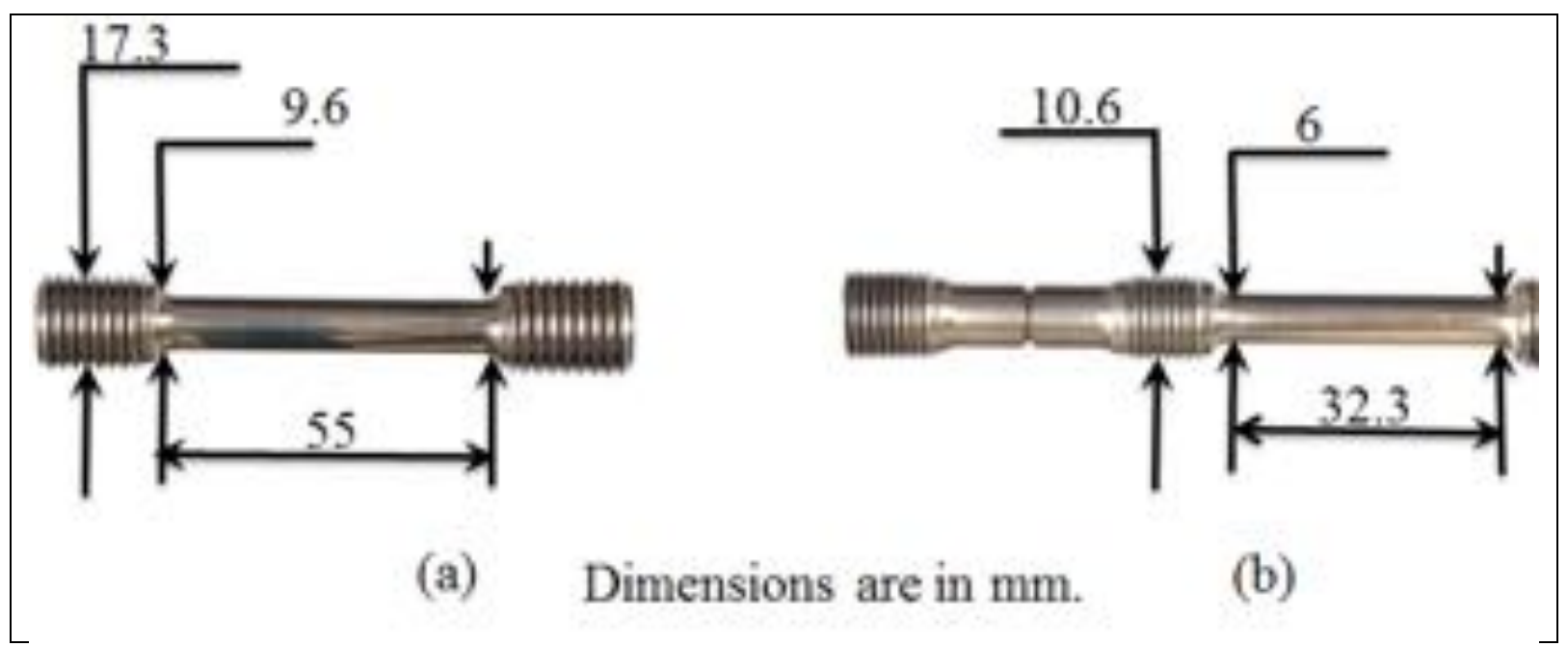

Figure 2: Schematic diagram illustrating the regions where the TEM samples have been taken from and the locations of hardness measurements. 


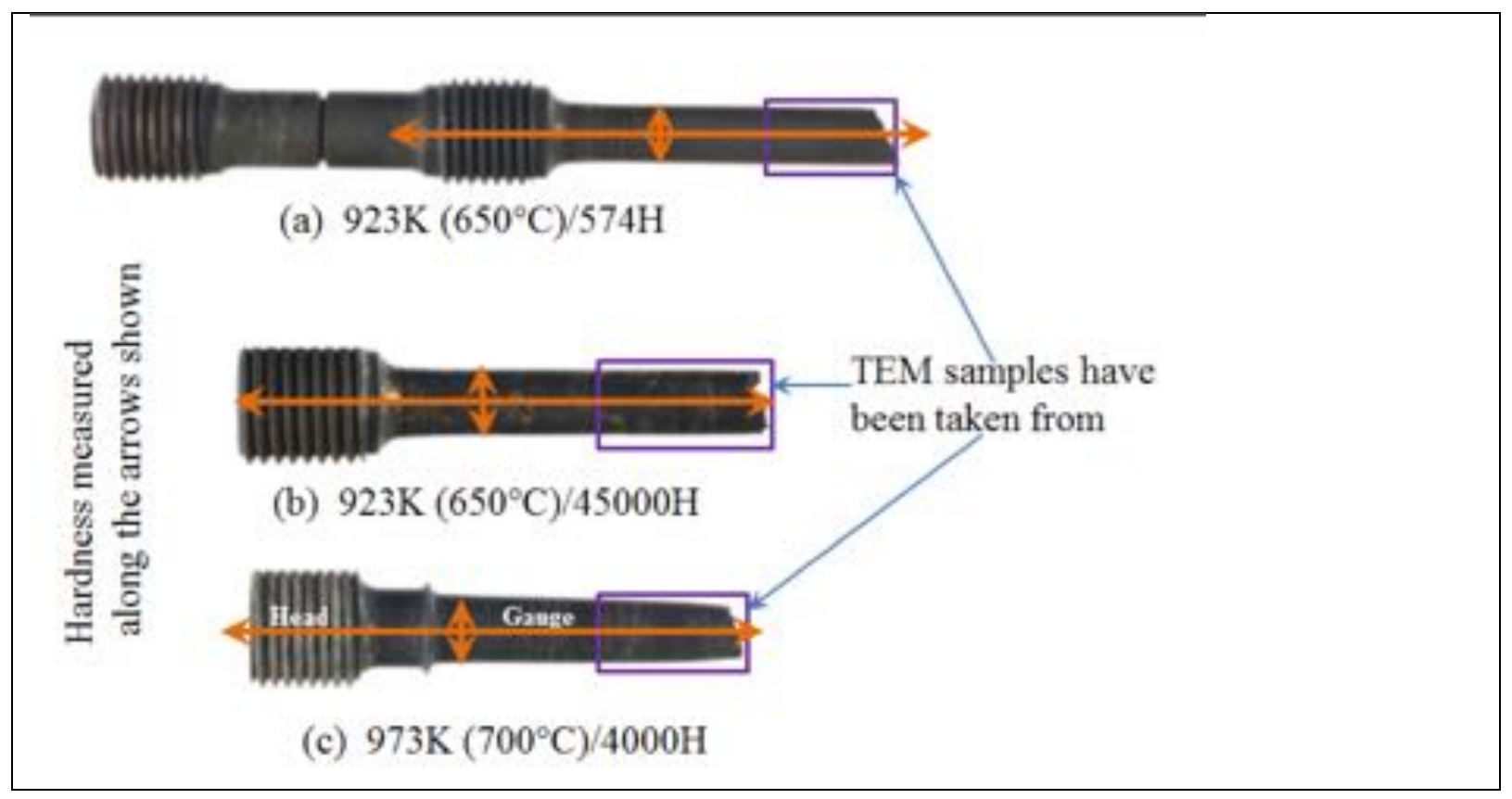

Figure 3: Spherical particles observed in a thin film via TEM. (a) The particles are at different positions through the thickness of the film and hence appear to overlap in a TEM image. (b) The actual area of particles observed in the TEM image.

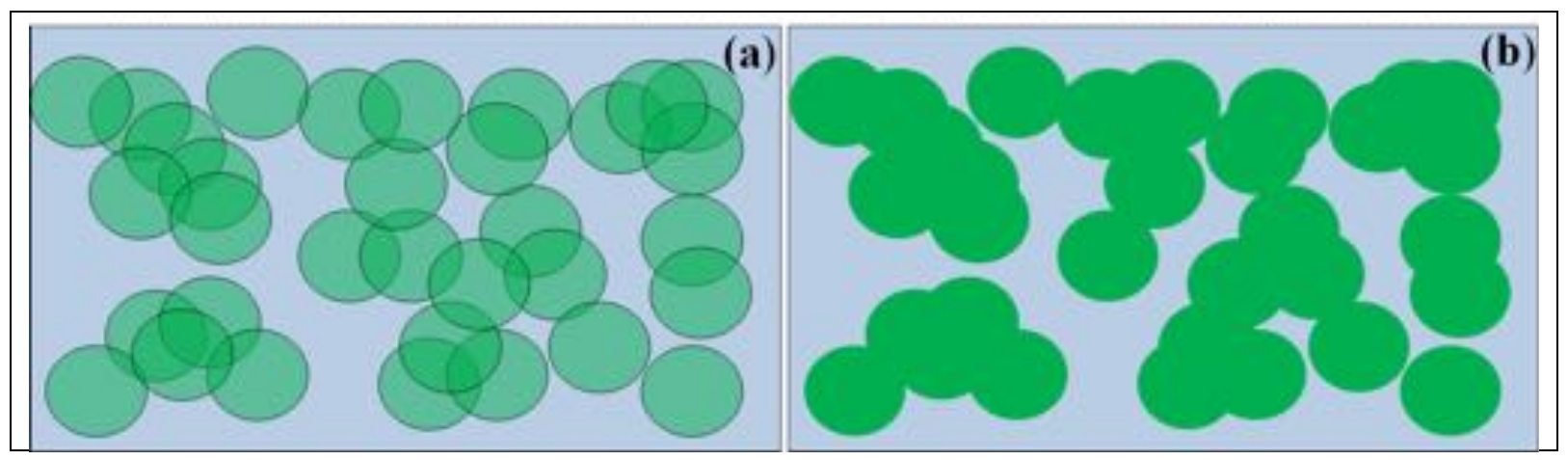

Figure 4: Optical micrographs montage showing the creep cracks penetrating into the gauge length (a) $923 \mathrm{~K}\left(650^{\circ} \mathrm{C}\right) / 574 \mathrm{~h},(\mathrm{~b}) 923 \mathrm{~K}\left(650^{\circ} \mathrm{C}\right) / 45000 \mathrm{~h}$ and (c) $973 \mathrm{~K}\left(700^{\circ} \mathrm{C}\right) / 4000 \mathrm{~h}$.

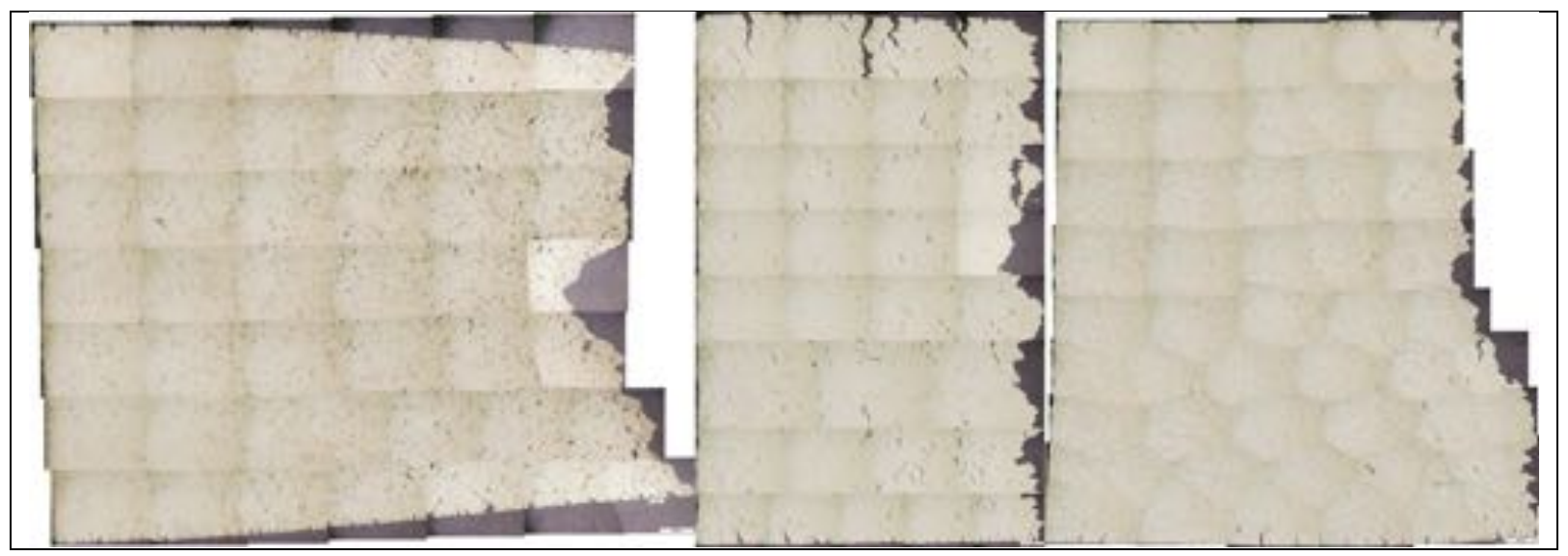


Figure 5: Vickers hardness versus LM parameter for creep-exposed Inconel 617 alloy at temperatures of $(923 \mathrm{~K}) 650^{\circ} \mathrm{C}$ and $973 \mathrm{~K}\left(700^{\circ} \mathrm{C}\right)$.

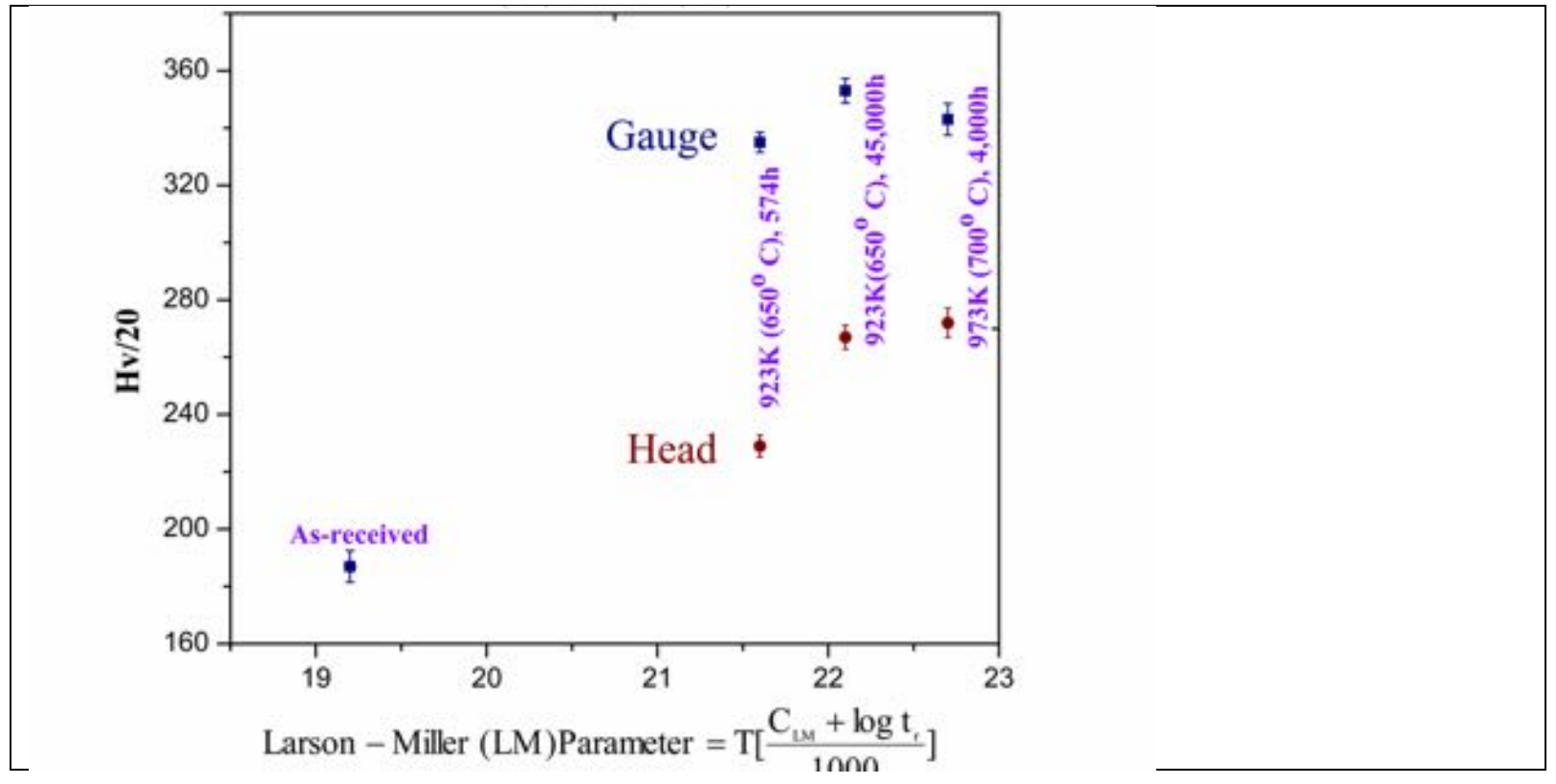

Figure 6: TEM micrograph showing the $\gamma^{\prime}$ precipitates, and indexed SAED pattern (inset) acquired from the $\gamma^{\prime}$ particles in the as-received sample. The beam direction was along [001].

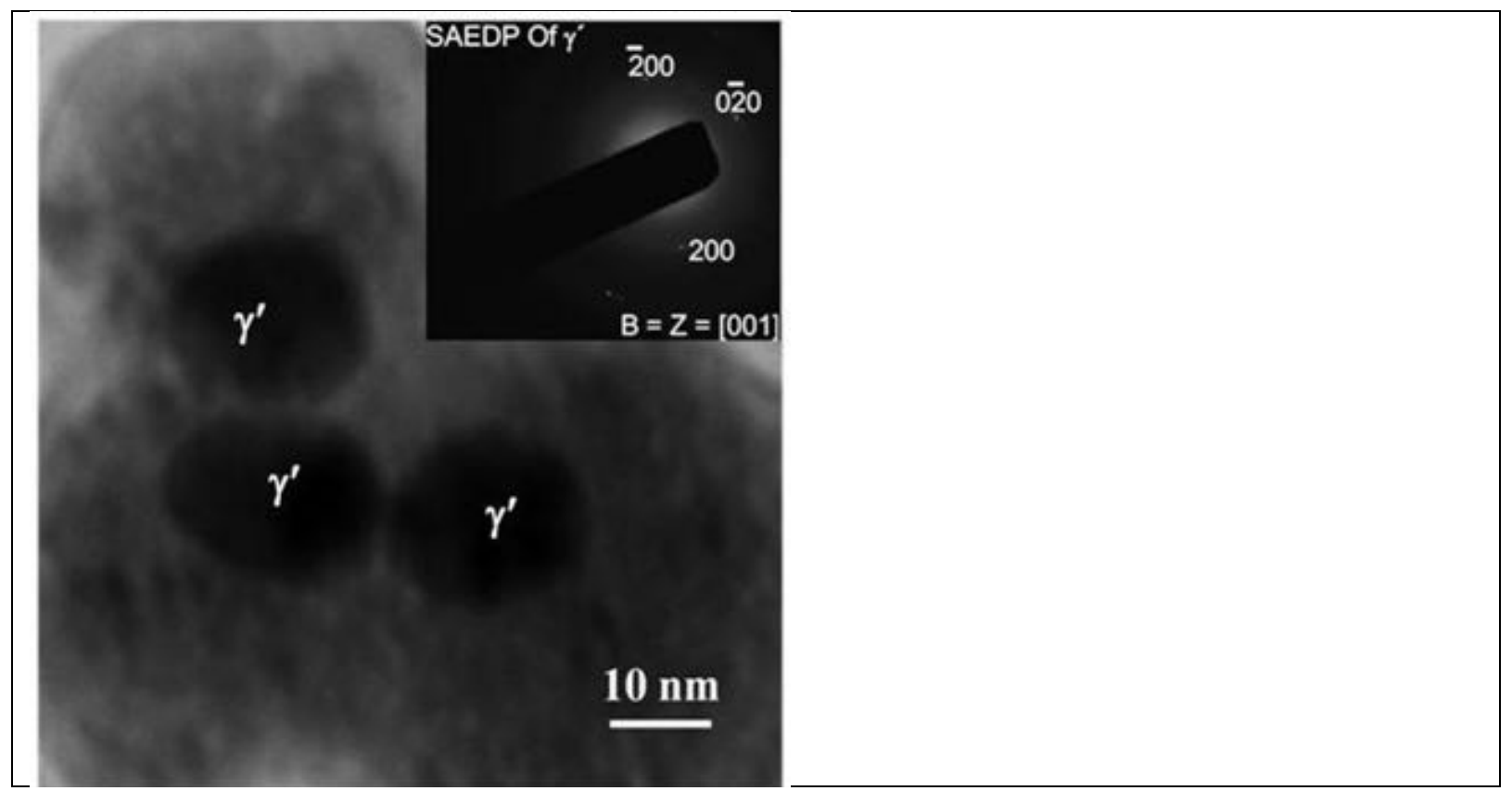

Figure 7: (a) TEM micrograph showing the $\gamma^{\prime}$ precipitates in a carbon replica from a sample creep exposed at $923 \mathrm{~K}\left(650^{\circ} \mathrm{C}\right)$ for 574 hours under intermediate stress; (b) Indexed SAEDP of $\gamma^{\prime}$ precipitates. Beam direction and zone axis were along $\mathrm{B}=[001]$. 


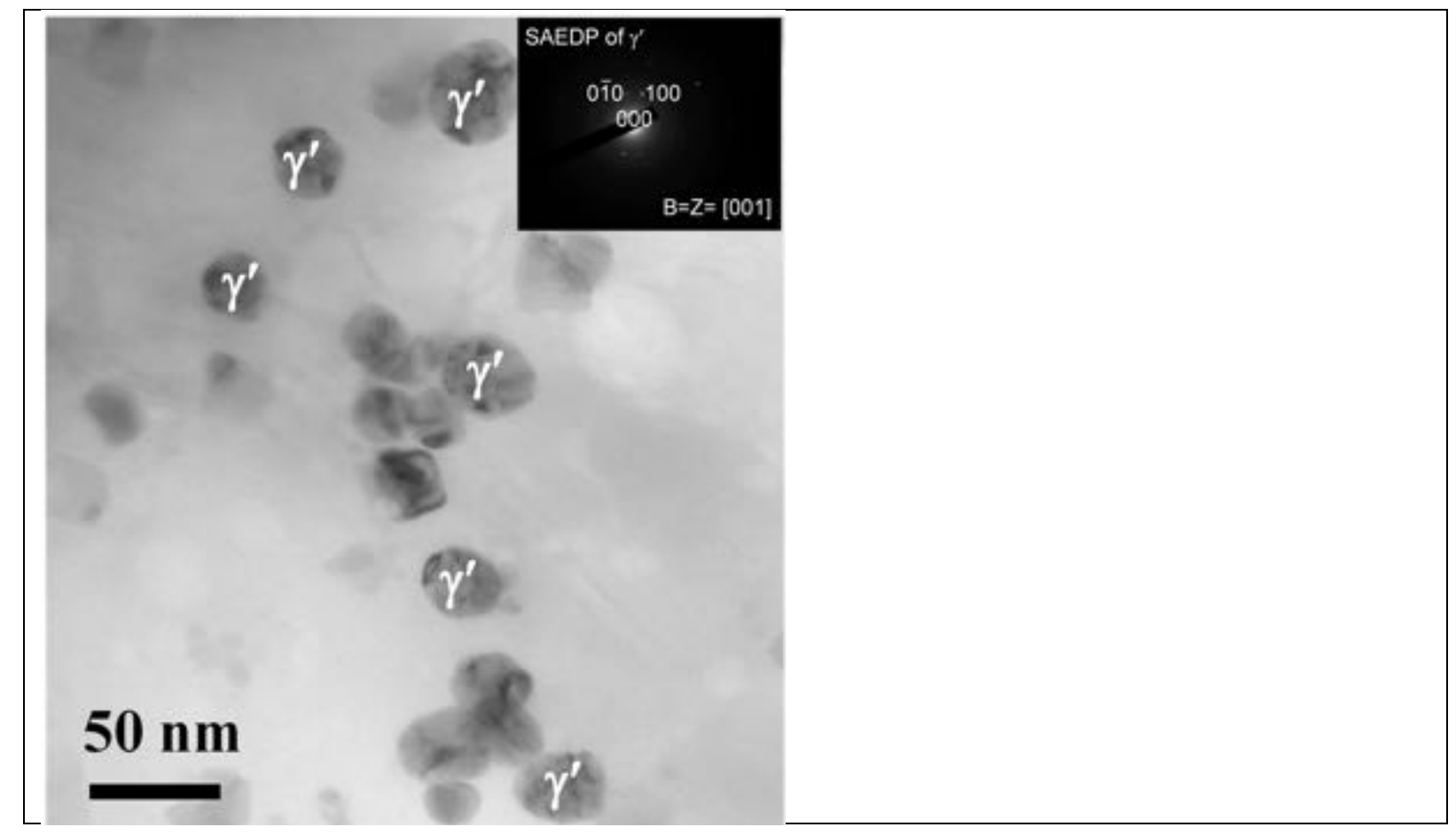

Figure 8: (a) TEM micrograph showing the $\gamma^{\prime}$ precipitates of spheroidal morphology in the sample creep exposed at $923 \mathrm{~K}\left(650^{\circ} \mathrm{C}\right)$ for $45,000 \mathrm{~h}$ under intermediate stress, and (b) SAEDP from $\gamma^{\prime}$ precipitates observed in (a). Beam direction and zone axis were along $\mathrm{B}=[001]$.

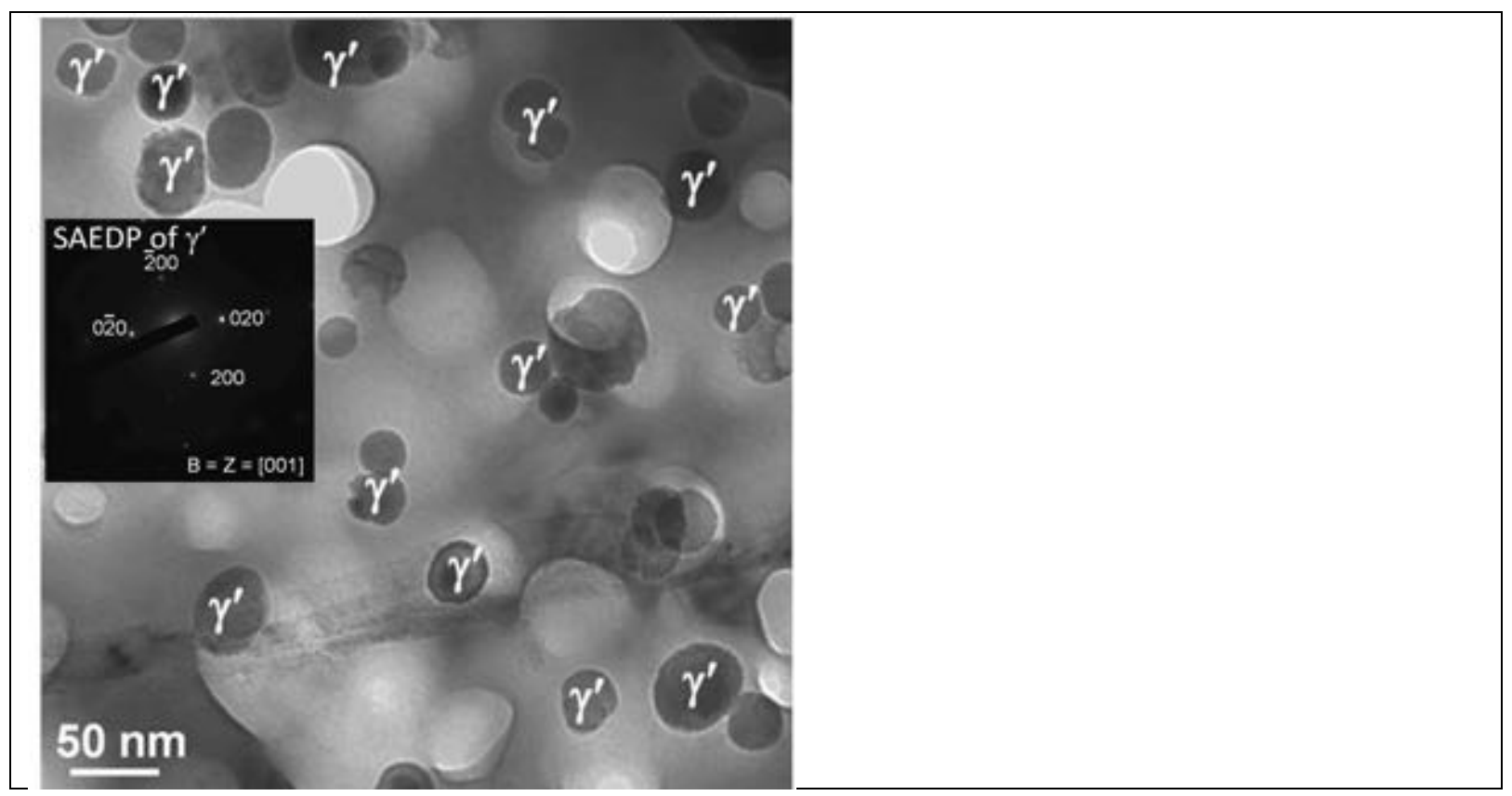

Figure 9: (a) TEM micrograph showing the spheroidal $\gamma^{\prime}$ precipitates uniformly distributed in the matrix of sample exposed at $973 \mathrm{~K}\left(700^{\circ} \mathrm{C}\right)$ for $4000 \mathrm{~h}$ under intermediate load, and (b) Indexed SAEDP from $\gamma^{\prime}$ precipitates from (a). The beam direction and zone axis were along $B=[011]$. 


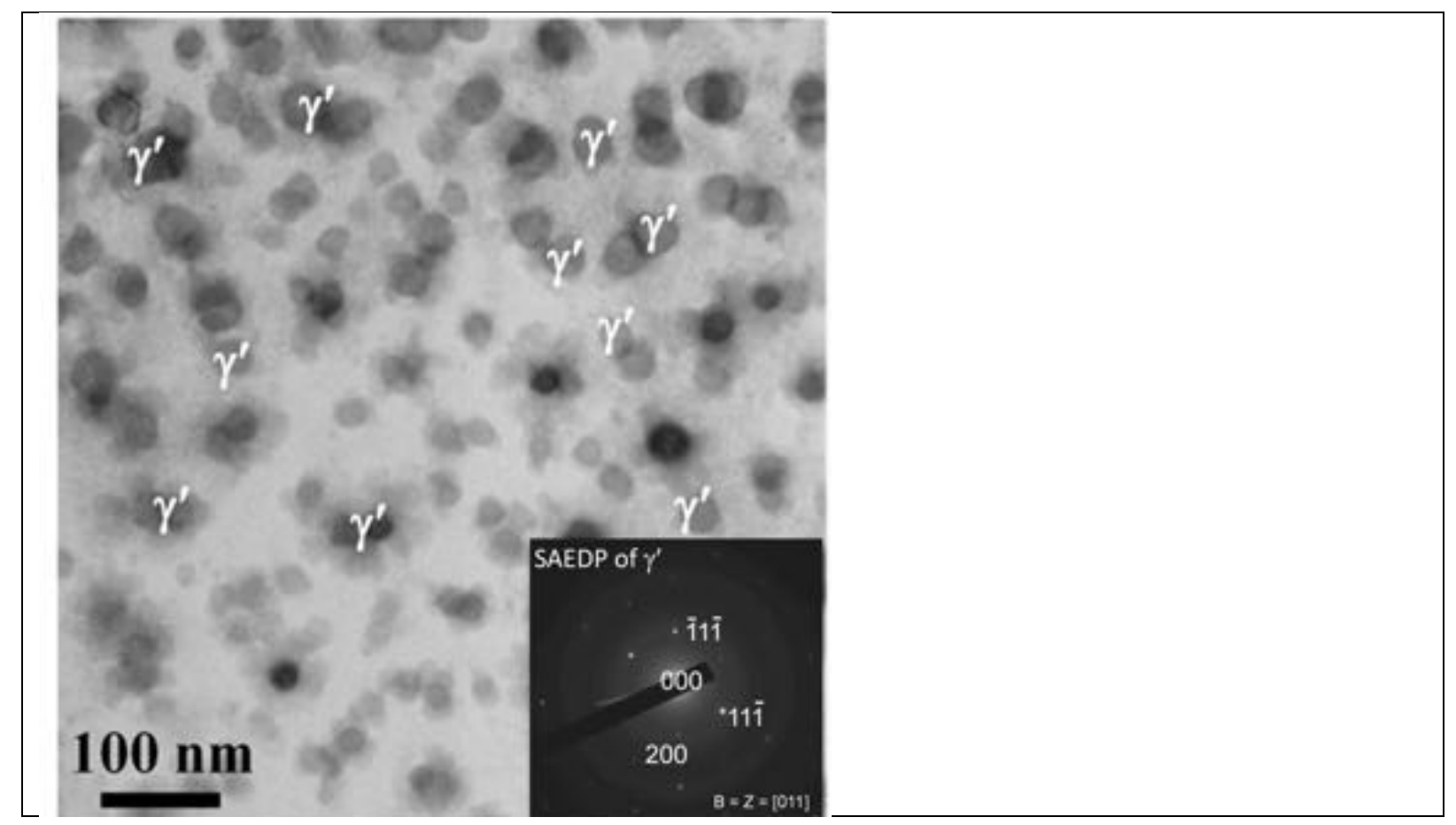

Figure 10: TEM micrograph illustrating dislocation structure, and dislocation-particle interactions in as-received sample. 


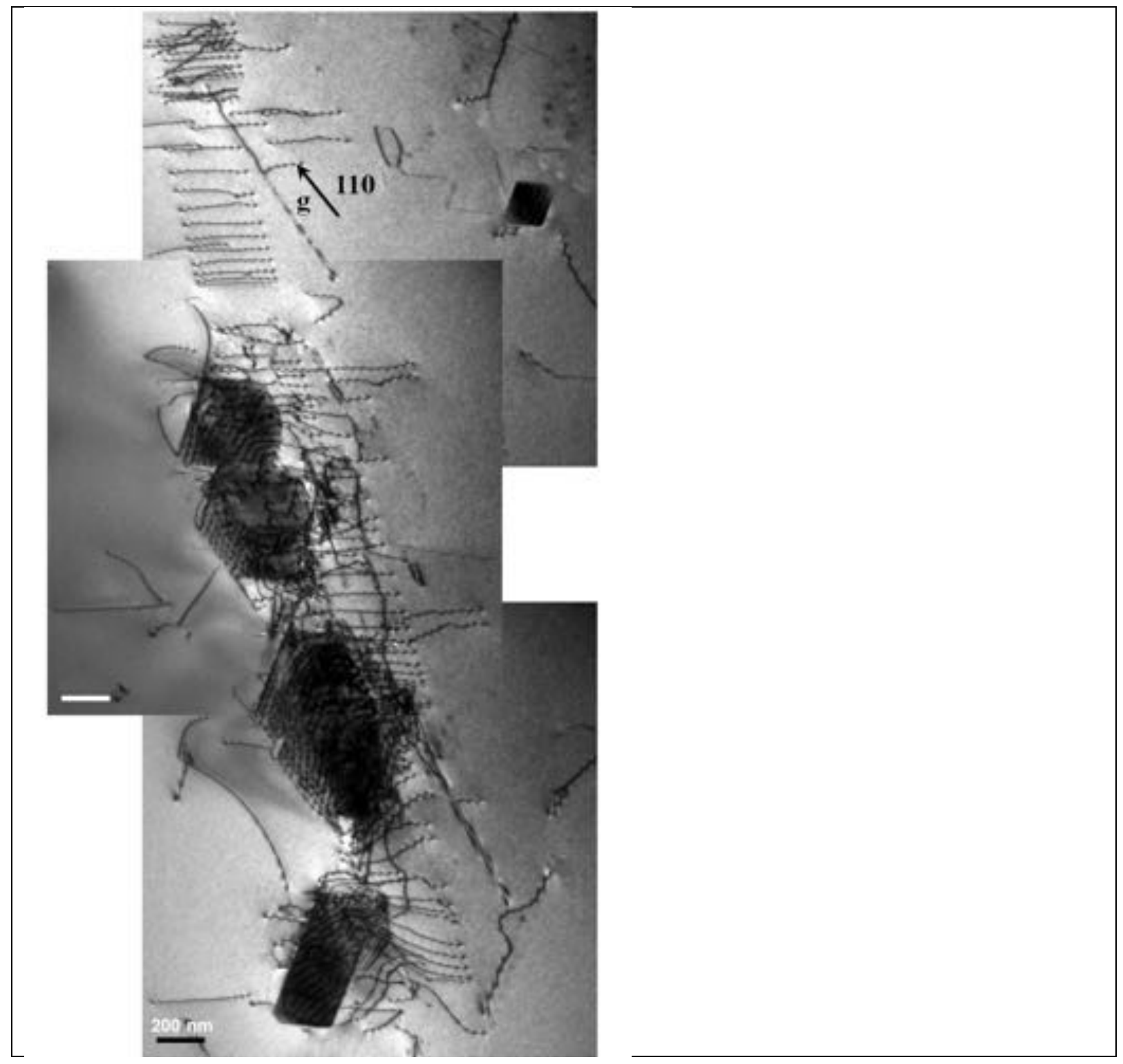

Figure 11: TEM micrograph illustrating dislocation structure, and dislocation-precipitate interaction in austenitic $\gamma$-matrix in sample creep-exposed at $923 \mathrm{~K}\left(650^{\circ} \mathrm{C}\right)$ for $574 \mathrm{~h}$. 


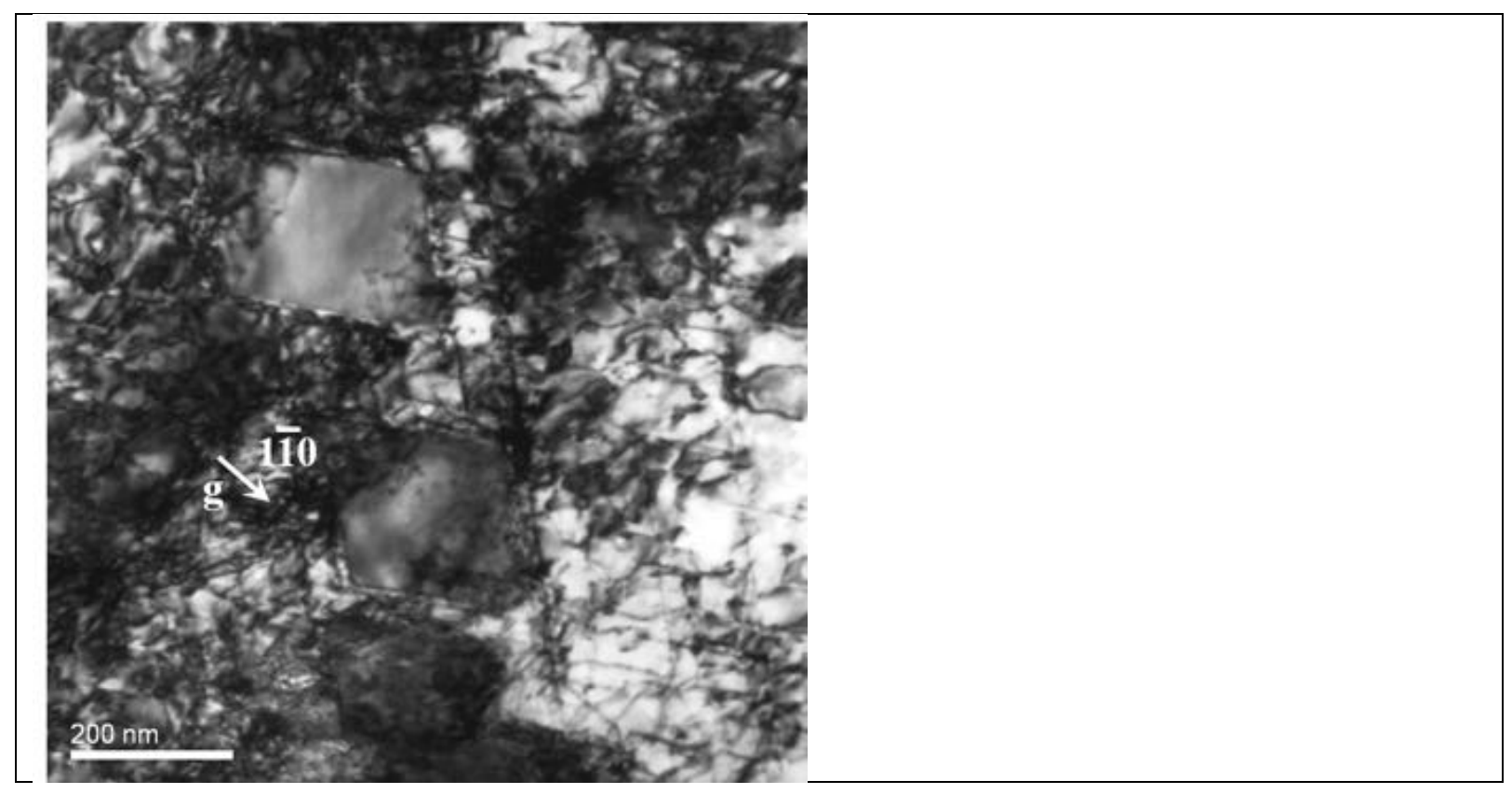

Figure 12: TEM micrograph for the sample creep-exposed at $923 \mathrm{~K}\left(650^{\circ} \mathrm{C}\right)$ for $45,000 \mathrm{~h}$ at intermediate stress. Precipitates in the micrograph are shown by arrow's heads.

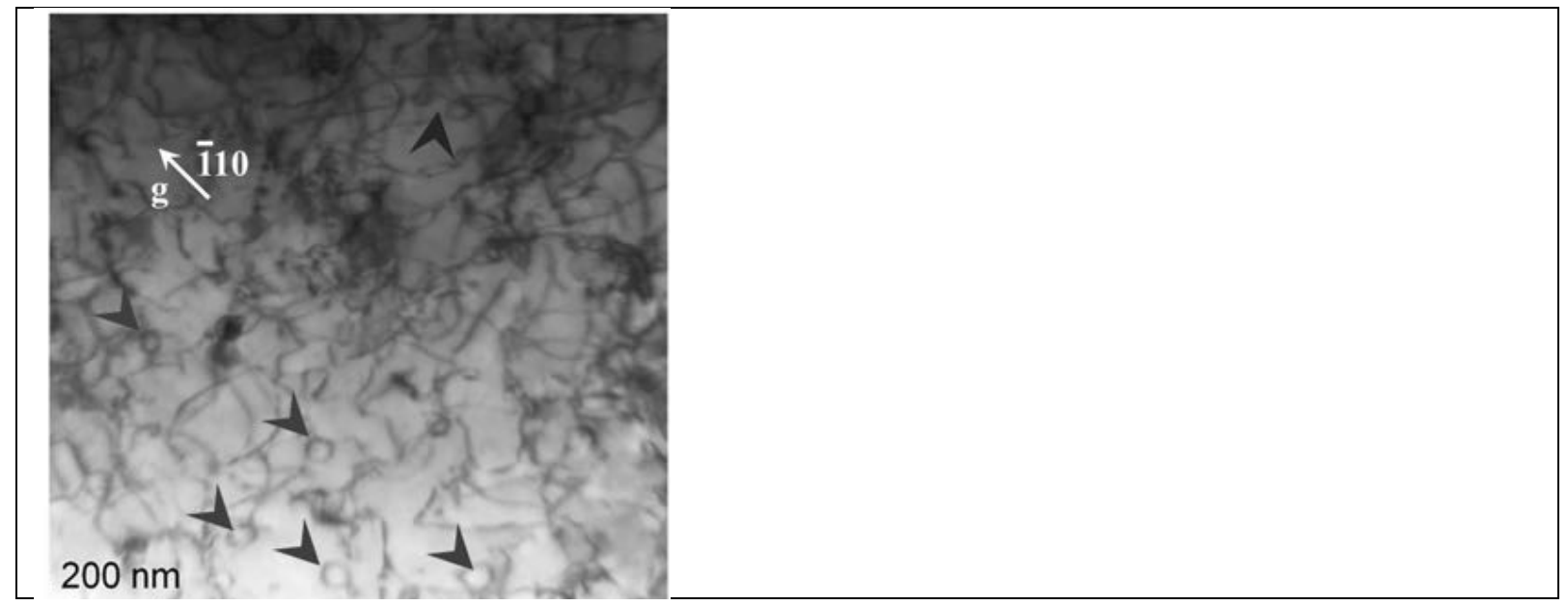

Figure 13: TEM micrograph for sample creep-exposed at $973 \mathrm{~K}\left(700^{\circ} \mathrm{C}\right)$ for $4000 \mathrm{~h}$. 


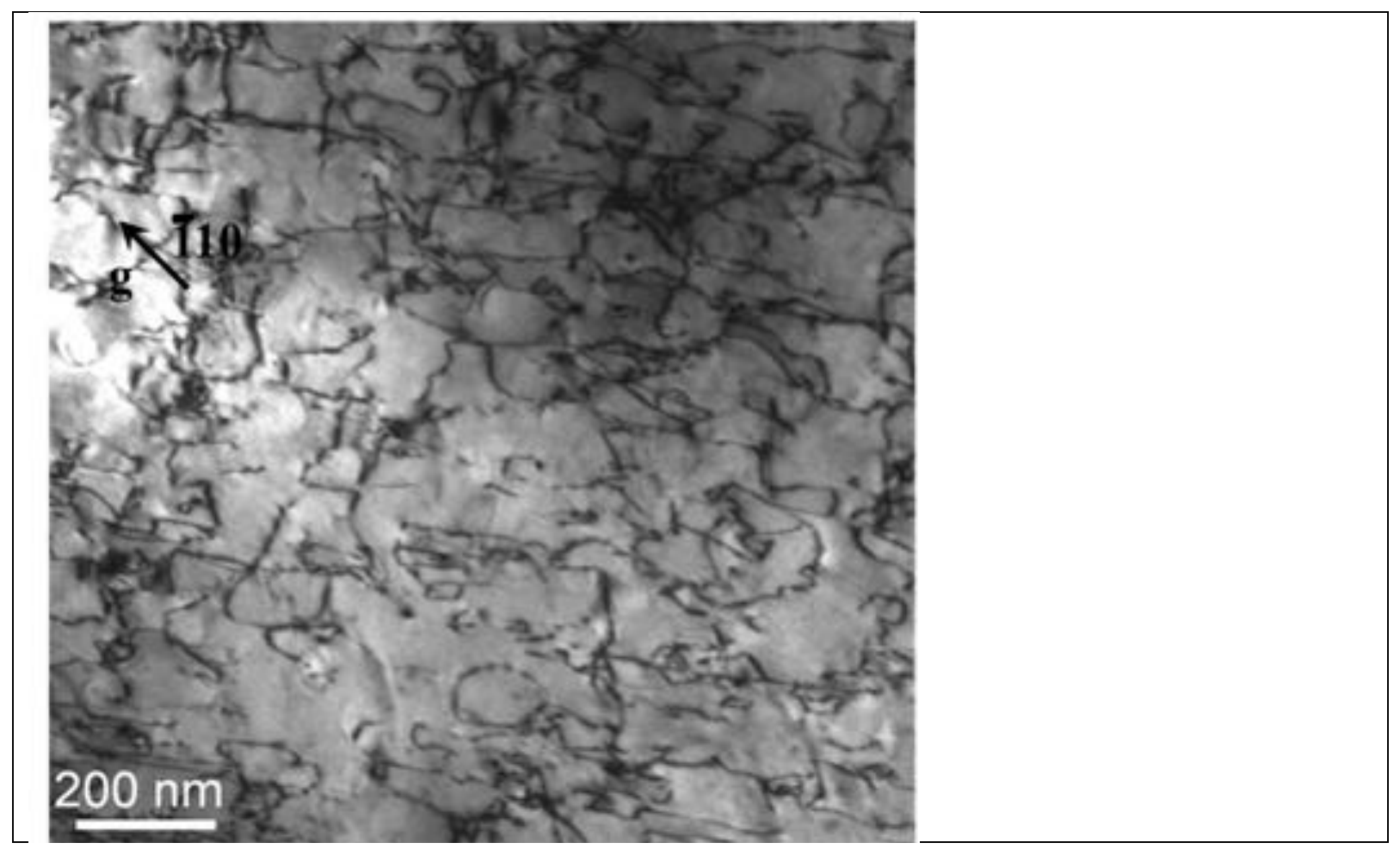

Figure 14: The variation in $\gamma^{\prime}$ and TiN volume percentage in IN617 with nitrogen content at $923 \mathrm{~K}\left(650^{\circ} \mathrm{C}\right)$ as predicted by ThermoCALC ${ }^{[30]}$.

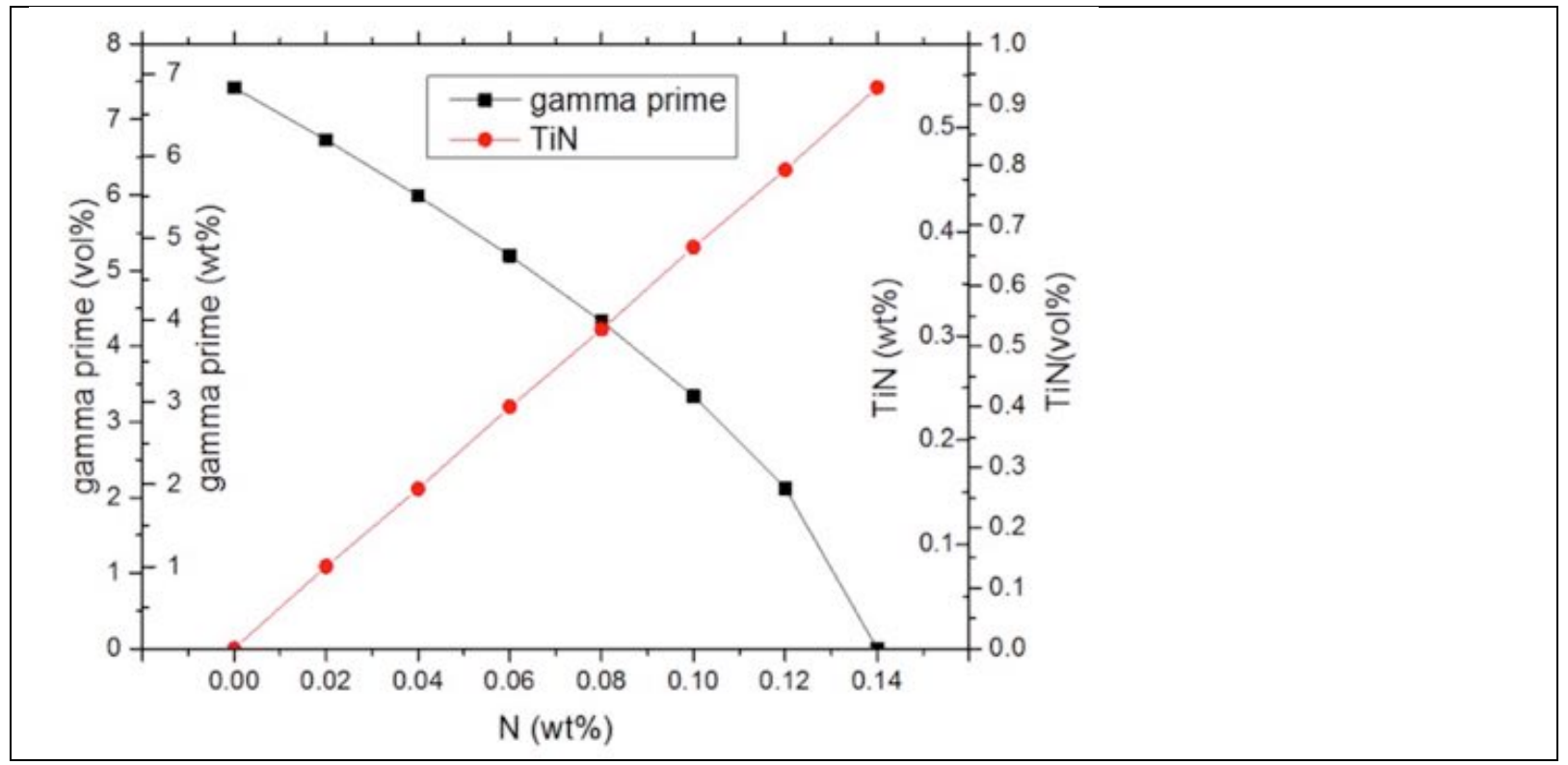

Figure 15: SEM micrographs of (a) edge of gauge length, (b) centre of gauge length, (c) edge of the head and (d) centre of the head of the sample $\left(923 \mathrm{~K}\left(650^{\circ} \mathrm{C}\right) / 574 \mathrm{H}\right)$; dark cuboidal precipitates are TiN particles. 


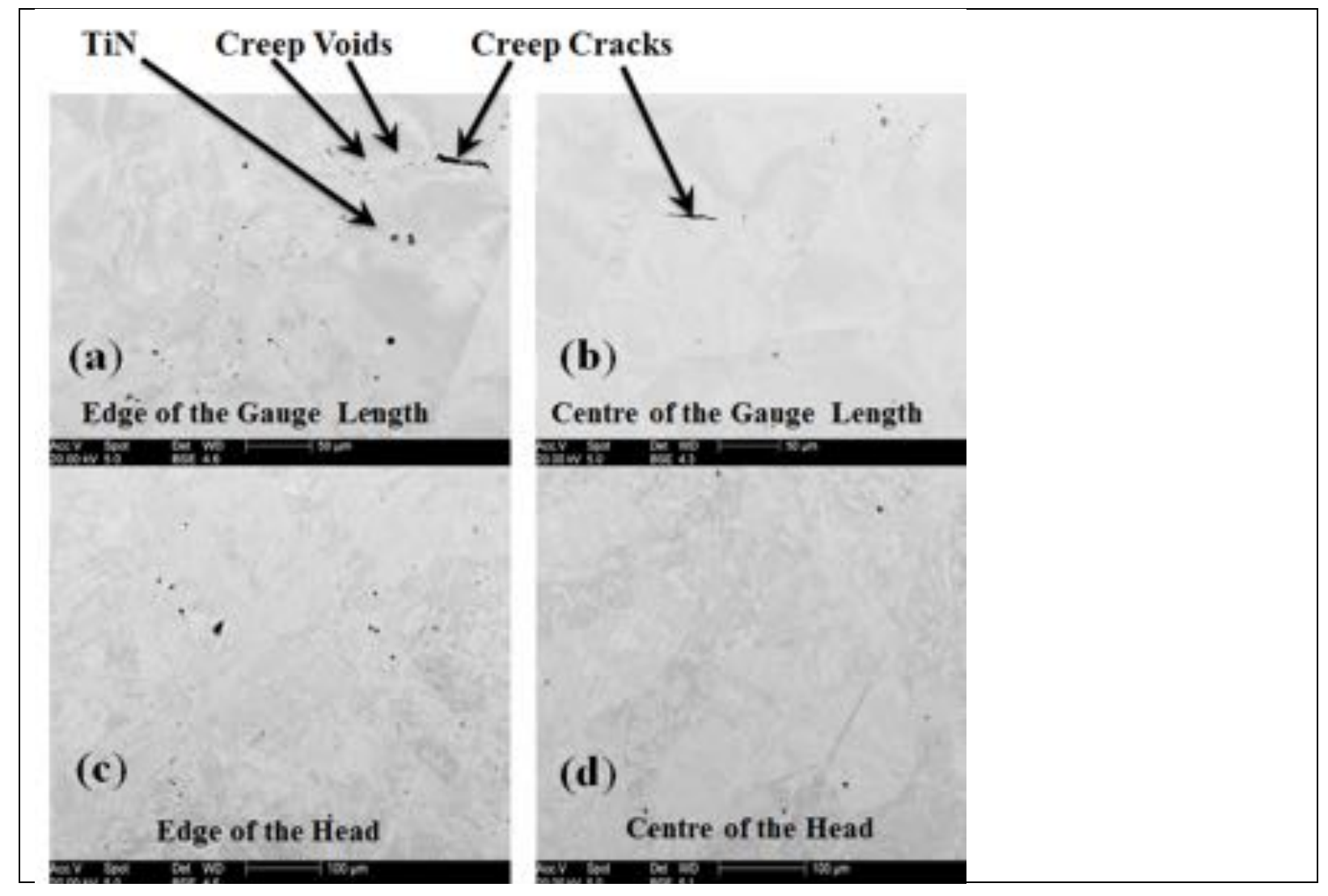

Figure 16: TEM image from carbon replica of $923 \mathrm{~K}\left(650^{\circ} \mathrm{C}\right) / 574$ hours creep exposed sample showing precipitates identified as TiN and $\gamma^{\prime}$ by SAEDP.

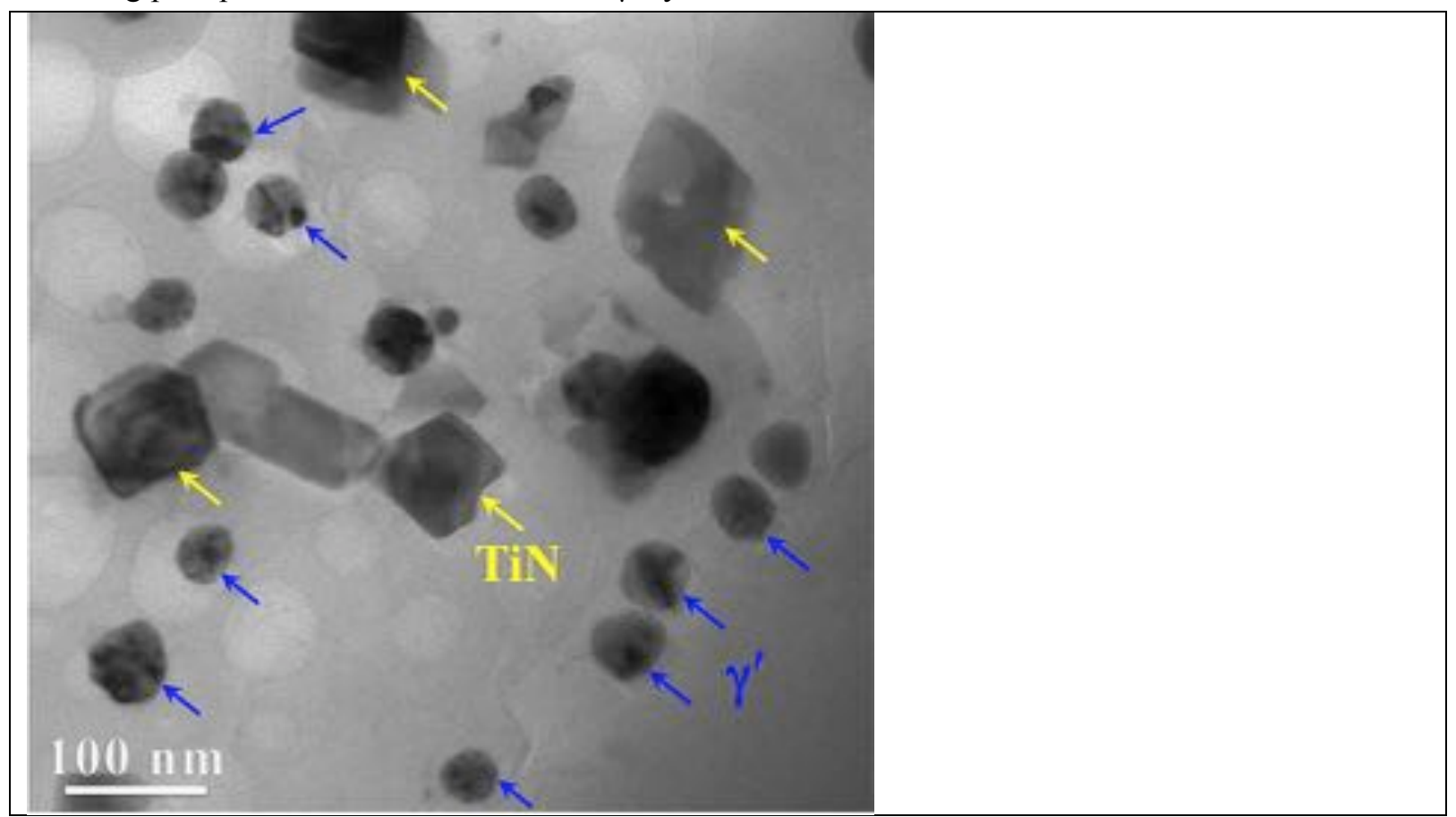

Figure 17: A comparison between observed and thermodynamically predicted volume fractions (\%) at $923 \mathrm{~K}\left(650^{\circ} \mathrm{C}\right)$ and $973 \mathrm{~K}\left(700^{\circ} \mathrm{C}\right)$ for $\gamma^{\prime}$ precipitates. 


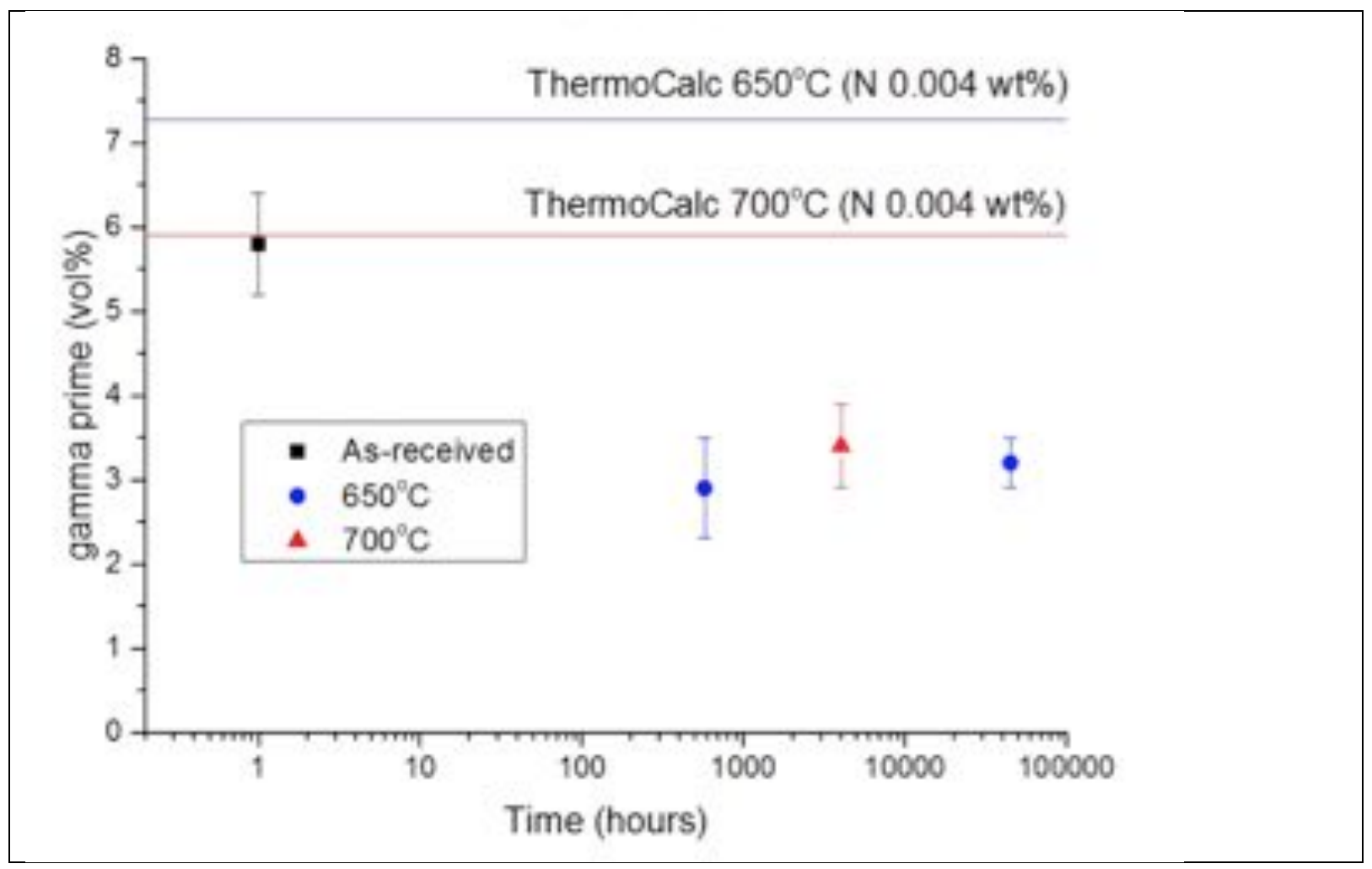

Figure 18: The change in hardness due to work hardening versus square root of dislocation density (dislocation density in lines $/ \mathrm{m}^{2}$ ) showing a reasonably proportional relationship.

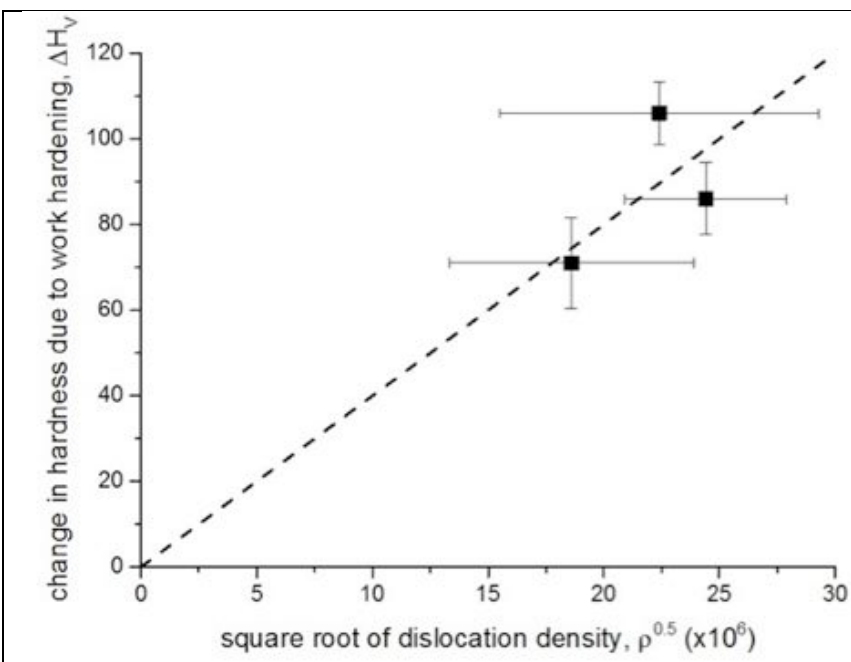

Figure 19: Cross-section through a thin film containing spherical particles. The centres of cut-particles exist within a distance of $\pm R$ of the sample surface giving it an effective thickness of $h+2 R$ in terms of the number of particles in the film. 


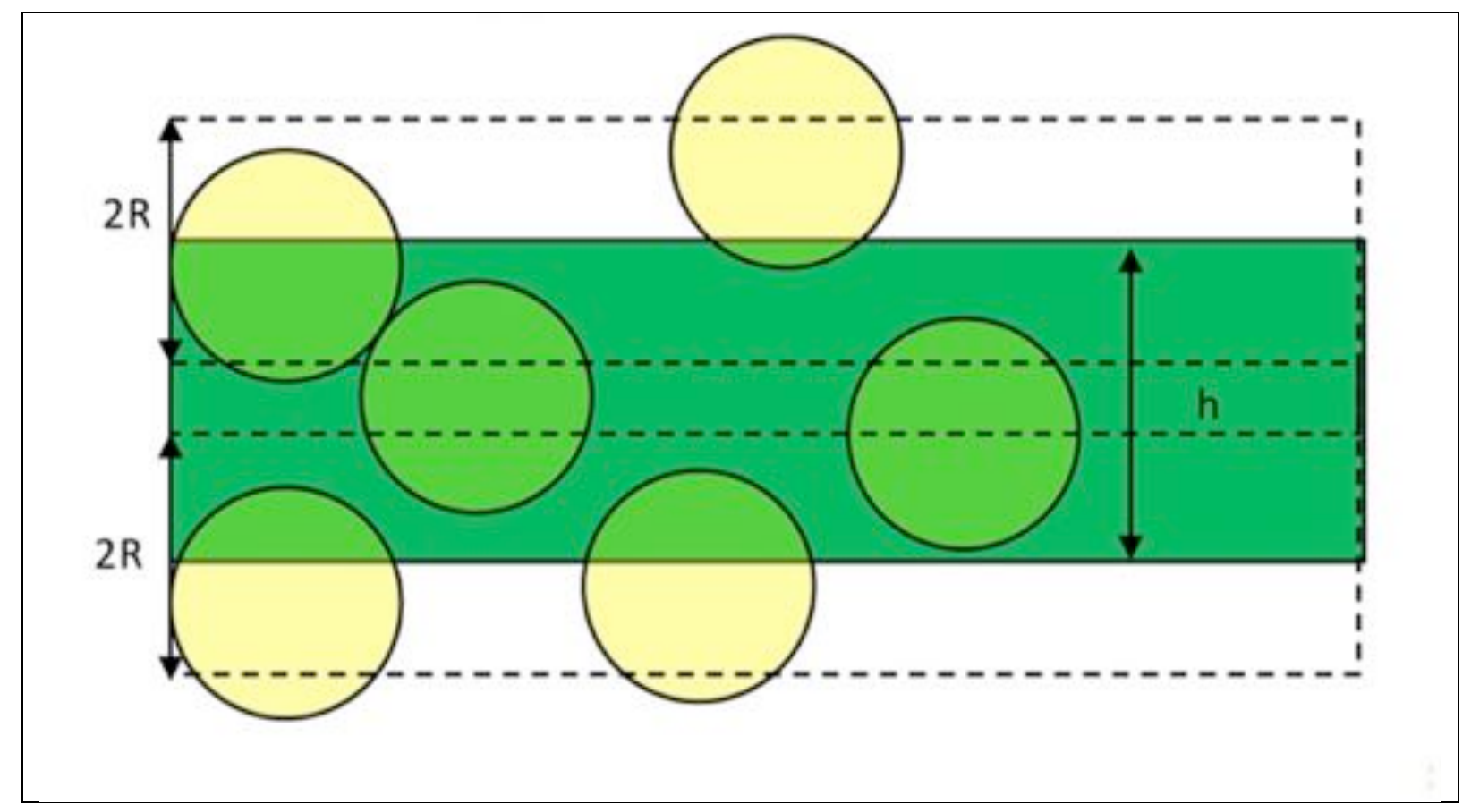

Figure 20: The relationship between the measured area fraction from a TEM micrograph and the actual volume fraction.

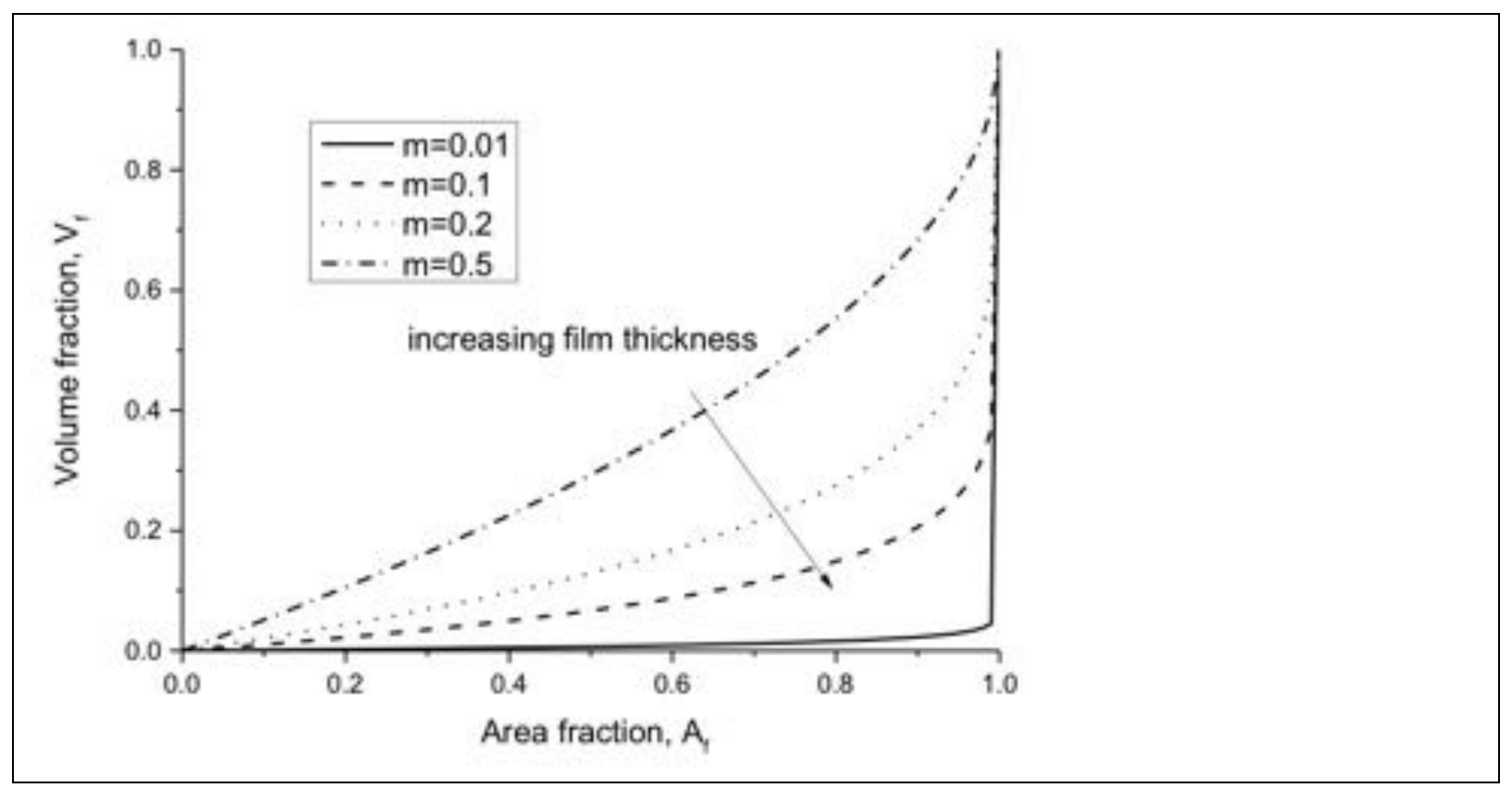

